\title{
Clinical practice guidelines for the management of metastatic colorectal cancer: a consensus statement of the Hellenic Society of Medical Oncologists (HeSMO)
}

\author{
Christos Dervenis ${ }^{\mathrm{a}}$, Evaghelos Xynos ${ }^{\mathrm{b}}$, George Sotiropoulosc, Nikolaos Gouvas ${ }^{\mathrm{d}}$, loannis Boukovinase, \\ Christos Agalianosf, Nikolaos Androulakis', Athanasios Athanasiadish , Christos Christodoulou', \\ Evangelia Chrysouj, Christos Emmanouilidisk, Panagiotis Georgiou', Niki Karachalioum, \\ Ourania Katopodin, Pandelis Kountourakiso, loannis Kyriazanosf, Thomas Makatsoris', \\ Pavlos Papakostas ${ }^{q}$, Demetris Pamamichael ${ }^{\circ}$, George Pechlivanides ${ }^{f}$, Georgios Pentheroudakis ${ }^{r}$, \\ Ioannis Pilpilidis', Joseph Sgourost, Paris Tekkis', Charina Triantopoulou", Maria Tzardiv, \\ Vassilis Vassiliouw, Louiza Vini ${ }^{x}$, Spyridon Xynogalosy, Nikolaos Zirasz, John Souglakos ${ }^{\&}$
}

Konstantopouleio Hospital of Athens, Greece; InterClinic Hospital of Heraklion, Greece; Laikon Hospital of Athens, Greece; Metropolitan Hospital of Piraeus, Greece; Bioclinic of Thessaloniki, Greece; Athens Naval and Veterans Hospital, Greece; Venizeleion Hospital of Heraklion, Greece; Koutlibaneion Hospital of Larissa, Greece; University Hospital of Heraklion, Greece; Interbalkan Medical Center, Thessaloniki, Greece; Chelsea and Westminster NHS Foundation Trust, London, UK; Dexeus University Institute, Barcelona, Spain; Iaso General Hospital, Athens, Greece; Oncology Center of Bank of Cyprus, Nicosia, Cyprus; University Hospital of Patras, Greece; Ippokrateion Hospital of Athens, Greece; University Hospital of Ioannina, Greece; Theageneion Cancer Hospital, Thessaloniki, Greece; Agioi Anargyroi Hospital of Athens, Greece; Iatriko Center of Athens, Greece; George Gennimatas General Hospital, Athens, Greece; Metaxas Cancer Hospital, Piraeus, Greece

\section{Abstract}

\begin{abstract}
There is discrepancy and failure to adhere to current international guidelines for the management of metastatic colorectal cancer (CRC) in hospitals in Greece and Cyprus. The aim of the present document is to provide a consensus on the multidisciplinary management of metastastic CRC, considering both special characteristics of our Healthcare System and international guidelines. Following discussion and online communication among the members of an executive team chosen by the Hellenic Society of Medical Oncology (HeSMO), a consensus for metastastic CRC disease was developed. Statements were subjected to the Delphi methodology on two voting rounds by invited multidisciplinary international experts on CRC. Statements reaching level of agreement by $\geq 80 \%$ were considered as having achieved large consensus, whereas statements reaching 60-80\% moderate consensus. One hundred and nine statements were developed. Ninety experts voted for those statements. The median rate of abstain per statement was $18.5 \%$ (range: $0-54 \%$ ). In the end of the process, all statements achieved a large consensus. The importance of centralization, care by a multidisciplinary team, adherence to guidelines, and personalization is emphasized. R0 resection is the only intervention that may offer substantial improvement in the oncological outcomes.
\end{abstract}

Keywords Colorectal cancer, metastatic disease, surgery, guidelines

Ann Gastroenterol 2016; 29 (4): 1-27

Conflict of Interest: The procedure was financially supported from Amgen Hellas and Sanofi Hellas

Correspondence to: Dr Nikolaos Gouvas, MD, PhD, General Surgeon, Metropolitan Hospital of Piraeus, Department of General Surgery, 9 Ethnarhou Makariou \& 1 El. Venizelou str, 18547, N. Faliro, Piraeus, Greece, Tel.: +30 210 4809000, +30 210 4807077,

e-mail: nikos.gouvas@gmail.com

Received 29 June 2015; accepted 10 March 2016; published online 3 June 2016

DOI: http://dx.doi.org/10.20524/aog.2016.0050

\section{Introduction}

Factors predisposing to metastases

An increased risk of metastases is anticipated in case of: 1) advanced primary disease (advanced $T$ stage, positive lymph nodes, presence of extramural venous invasion, poor differentiation) [1-3]; 2) female gender [3]; 3) location at the rectum [3]; or at left than the right colon [4]; 4) increased CD-10 expression [5]; 5) KRAS and PIK3CA 
bi-mutations; 6) presence of metabolic syndrome [6]; and 7) and increased serum levels of carcinoembryonic antigen (CEA) (>5 ng/mL) alanine aminotransferase, aspartate aminotransferase, glutamyltraferase, Lactate Dehydrogenase (LDH), Vascular Endothelial Growth Factor Receptor (VEGFR) and Tissue Inhibitor of Metalloproteinases 1 (TIMP1) $[1,7]$. In contrast, patients with hepatitis $B$ virus infection present a reduced risk of liver metastasis and increased rate of $\mathrm{R} 0$ resections, but also increased risk of extra-hepatic metastasis [8]. There is some evidence that portal vein chemotherapy with 5-fluorouracil (5-FU) could be an effective preventive measure for liver metastases. According to a recent study [9], 5-year liver metastasis rate is $12.5 \%$ after curative surgery for the primary tumor combined with portal vein chemotherapy, as opposed to a $25 \%$ relative rate after curative surgery alone.

\section{Aim}

The Hellenic Society of Medical Oncology (HeSMO) selected an executive team on the grounds of their experience in colorectal cancer (CRC) and hepato-biliary and pancreatic malignancies which was assigned to develop a consensus statement and form guidelines on the main aspects of image staging, surgical treatment and follow up of metastatic CRC, based on the review of literature and the principles of the evidence-based medicine.

The present draft is part of a large consensus on the guidelines for the management of colo-rectal cancer. Guidelines on: 1) epidemiology, molecular biology, genetics, prognostic and predictive markers, hereditary forms, surveillance; 2) colon cancer care; 3) rectal cancer care; and 4) adjuvant treatment of CRC are presented elsewhere.

\section{Methodology}

The methodology in setting our guidelines for the surgical management of rectal cancer has already been reported elsewhere [10]. The first round of the online Delphi voting process opened on September 29 2013 and closed on December $6^{\text {th }} 2013$. The second round opened on January $6^{\text {th }} 2014$ and closed on January $24^{\text {th }} 2014$. In the final document, all statements are presented as recommendations of care. Even statements achieving a consensus of $<80 \%$ were included. At the end of each recommendation the level of evidence (LOE) and the strength of recommendation (SOR) are mentioned, followed by the rate of voting consensus (ROVC) (Table 1).

\section{Legal disclaimer}

Details on the legal aspects of these guidelines have already been reported [10].

\section{Discussion}

Ninety experts participated in the Delphi methodology and voted for 101 statements. Median abstain rate was 18.5\% (0-54\%). After the first voting process, 24 statements achieved a $100 \%$ voting consensus by all participants. There were 61 statements achieving a 90-99\% consensus, and 13 achieving a consensus rate of $80-89 \%$. Three statements achieved a rate of consensus of less than $80 \%$. These three statements were circulated among the members of the executive team and, after being amended, they re-entered a second round of voting. Also, seven new statements entered directly the second voting round making the total number of statements 108. At the end of the process, there were no statements with a ROVC of less than $80 \%$ (Table 2).

Table 1 Evidence level and recommendation grade

Level of evidence

\begin{tabular}{ll}
\hline I & $\begin{array}{l}\text { Evidence from at least one large RCT of good methodological } \\
\text { quality (low potential for bias) or meta-analyses of } \\
\text { well-conducted RCTs without heterogeneity }\end{array}$ \\
II & $\begin{array}{l}\text { Small RCTs or large RCTs with a suspicion of bias (lower } \\
\text { methodological quality) or meta-analyses of such trials or of } \\
\text { trials with demonstrated heterogeneity }\end{array}$ \\
III & Prospective cohort studies \\
IV & Retrospective cohort studies or case-control studies \\
V & Studies without control group, case reports, experts opinions \\
\hline
\end{tabular}

Strength of recommendation

\begin{tabular}{cl} 
A & $\begin{array}{l}\text { Strong evidence for efficacy with a substantial clinical benefit, } \\
\text { strongly recommended }\end{array}$ \\
B $\quad \begin{array}{l}\text { Strong or moderate evidence for efficacy, but with a limited } \\
\text { clinical benefit, generally recommended }\end{array}$ \\
C $\quad \begin{array}{l}\text { Insufficient evidence for efficacy or benefit does not outweigh } \\
\text { the risk or the disadvantages (adverse events, costs) optional }\end{array}$ \\
D $\quad \begin{array}{l}\text { Moderate evidence against efficacy or for adverse outcome, } \\
\text { generally not recommended }\end{array}$ \\
E $\quad \begin{array}{l}\text { Strong evidence against efficacy or for adverse outcome, } \\
\text { never recommended }\end{array}$ \\
\hline RCT, randomized control trial
\end{tabular}

Table 2 Rate of voting consensus of statements after the two voting processes

\begin{tabular}{lccc}
\hline $\begin{array}{l}\text { Rates of } \\
\text { voting } \\
\text { consensus }\end{array}$ & $\begin{array}{c}\text { Statement } \\
\text { numbers after } \\
\text { 1st voting process }\end{array}$ & $\begin{array}{c}\text { Resubmitted } \\
\text { statement } \\
\text { numbers }\end{array}$ & $\begin{array}{c}\text { Statement } \\
\text { numbers at the } \\
\text { end of process }\end{array}$ \\
\hline $100 \%$ & 24 & & 24 \\
$90-99 \%$ & 61 & & 69 \\
$80-89 \%$ & 13 & 1 & 15 \\
$70-79 \%$ & 1 & 2 & \\
$60-69 \%$ & 2 & 7 & \\
$\begin{array}{l}\text { New } \\
\text { statements }\end{array}$ & Total: 101 & Total: 10 & Total: 108 \\
\hline
\end{tabular}




\section{General considerations}

\section{Background}

All patients with metastatic CRC, and in particular candidates for resection, should be discussed and managed in the context of a multidisciplinary team (MDT) [11]. Such a team should comprise the necessary medical and nonmedical team members (Diagnostic: radiologists, pathologists; Therapeutic: colorectal, hepato-biliary and thoracic surgeons, medical oncologists, radiotherapist, palliative care medicinal personnel; and Others: nursing). Treatment of metastatic CRC should be personalized and based on multimodality measures. Also, it has been documented that liver surgery in high-volume centers, practiced by highly specialized and experienced personnel, is associated with better outcomes including morbidity, perioperative mortality and survival [12-14].

\section{RECOMMENDATIONS}

1. Treatment should be personalized, based on multimodality measures and after MDT meeting discussions (SOR A) (ROVC: 100\%)

2. Centralization of management offers the best shortterm outcomes, namely mortality of $5 \%$ and 90 -day morbidity of $30-40 \%$ after hepatic resection (SOR A) (ROVC: 97\%)

Imaging of metastatic disease - other staging modalities

\section{Background}

Chest $\mathrm{x}$-ray may be the initial approach to detect pulmonary metastasis, but in general thoracic and abdominal computed tomography (CT) is recommended to detect or rule out distant metastases. The real value of CT is its accuracy in detecting distant metastases. Magnetic resonance imaging (MRI) is helpful in further characterization of liver lesions suspected for metastases diagnosed by CT scan or ultrasound (US) [15]. MRI is the preferred first-line modality for evaluating colorectal liver metastases in patients who have previously undergone treatment, and for resolving diagnostic problems with equivocal lesions. In a recent meta-analysis [16], MRI sensitivity in detection of colorectal metastases was higher than of CT, particularly for small lesions $(<10 \mathrm{~mm})$. In an even more recent report enhanced MRI was proven more accurate than multi-detector CT (MDCT) or US for the evaluation of liver metastases [15]. Enhanced MRI with diffusion-weighted series is more sensitive and accurate in detecting CRC liver metastases than the non-enhanced MRI [17].

Fluorodeoxyglucose-positron emission tomography (FDGPET) could be considered for detection of liver metastases and peritoneal disease when there is clinical, biochemical or radiological suspicion of systemic disease [18]. FDGPET is mainly useful in the assessment of local recurrence and metastatic disease, when conventional imaging is not helpful [19]. Furthermore, PET/CT is more accurate than CT alone in detection of metastatic disease, in patients with high suspicion for recurrence [20]. Also, PET/CT is more reliable than MDCT for the detection of small subcapsular liver metastatic deposits [21]. Currently, FDG-PET is not used as a primary staging modality in CRC. Bone scan and brain imaging are only helpful in case of relevant clinical symptoms.

There is a limited benefit from laparoscopic staging of CRC metastatic disease with the use of US. According to a recent meta-analysis [22], laparoscopic US staging has a low sensitivity of $59 \%$, and is only recommended as an additional diagnostic modality to suspected peritoneal carcinomatosis. None of the available imaging or intraoperative diagnostic modalities is sensitive or accurate in the assessment of the lymph nodes at the hepatic hilum [23].

\section{RECOMMENDATIONS}

3. Abdominal CT or MRI is required to detect liver metastasis (LOE V; SOR B) (ROVC: 98\%)

4. US is less accurate than MRI in the detection of liver metastases (LOE I, SOR A) (ROVC: 95\%)

5. Chest X-ray and, preferably chest $\mathrm{CT}$ is recommended for the detection of pulmonary metastases (LOE V; SOR B) (ROVC: 95\%)

6. MRI is the preferred imaging modality for the evaluation of previously treated colorectal cancer on equivocal liver metastases (LOE IV; SOR B) (ROVC $89 \%)$

7. FDG-PET should not be routinely used for the detection of metastatic disease, unless there is biochemical evidence of recurrent disease in the absence of apparent lesion (LOE V; SOR D) (ROVC: 100\%)

8. Bone scan and brain imaging should only be performed for patients presenting relevant symptoms (LOE V; SOR D) (ROVC: 97\%)

9. Laparoscopic staging of liver metastasis with the use of US is of limited accuracy (LOE I, SOR A) (ROVC: $84 \%)$.

\section{Management of resectable liver metastases (Fig. 1)}

\section{Indications for surgical resection}

\section{Background}

$\mathrm{R} 0$ resection is the treatment of choice for the CRC metastatic liver disease. For patients with resectable liver metastases surgical resection offers the best chance for long-term survival with actuarial 5-year survival rates ranging from $30 \%$ to $58 \%$ in some selected series, and a cure rate of $20 \%$ [24-26]. However, disease relapses, mostly in the liver, in $60-75 \%$ of these patients. In general, criteria for resectability of liver or lung metastases are not standardized and have evolved over the last years. They are clearly related to the experience of the surgeon and the 


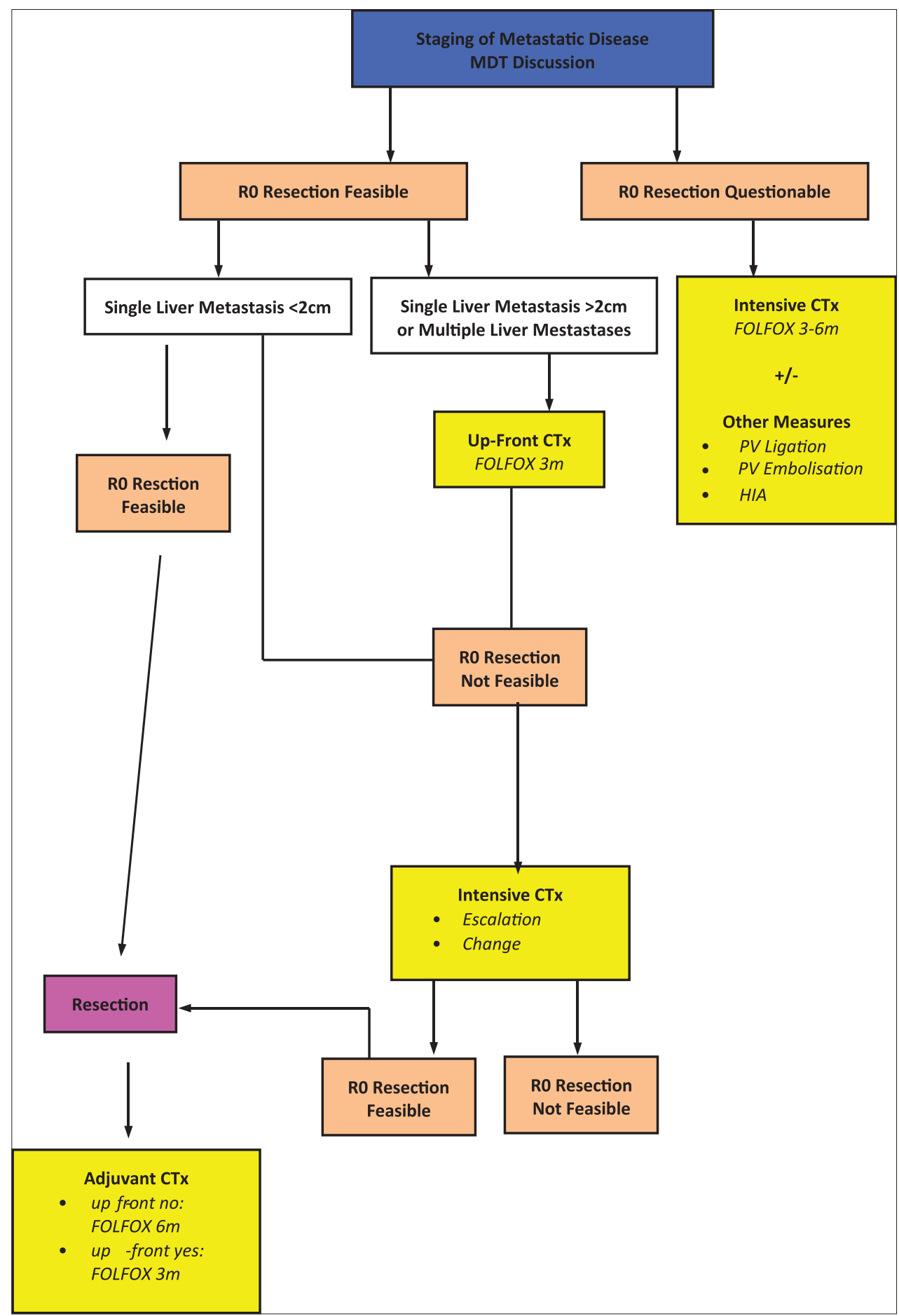

Figure 1 Strategy and treatment algorithm of metachronous resectable metastases (liver +/- lungs)

$M D T$, multi-disciplinary team; CTx, chemotherapy; $P V$, portal vein; HAI, hepatic arterial infusion chemotherapy;

FOLOX, 5-fluoro-uracil plus oxaliplatin

MDT assessment. Based on data from old series, unresectable disease is considered in the presence of: 1) more than four metastatic lesions; 2) bilobar disease; 3) extrahepatic disease; and 4) inability to achieve resection margins of at least $1 \mathrm{~cm}[27,28]$. None of these factors is considered now as absolute contraindication for surgery; however, patients with these characteristics are those who have a worse prognosis. Current indications for resection of CRC liver metastases, are removal of all deposits with adequate clear margin, and preservation of sufficiently function of hepatic parenchyma. A prerequisite for resection of liver metastases is a functioning remnant of at least $30 \%$ of the total volume of the liver. Resectional surgery should 
not endanger patient's life because of unsuitable location of metastases. The ability to achieve $\mathrm{R} 0$ resection and assessment of the volume of healthy liver remnant should be determined by the radiologist and surgeon preoperatively. MDCT-volumetry is considered as the method of choice to estimate remaining liver volume [29-31]. Furthermore, MR spectroscopy can be applied for the assessment of liver steatosis in patients who have received neo-adjuvant chemotherapy [32]. Additional considerations, prior to deciding resection of liver metastases, are any possible extrahepatic recurrence and poor tumor biology, as these factors adversely affect outcomes.

\section{RECOMMENDATIONS}

10. Hepatic R0 resection is the treatment of choice for liver metastases, associated with a 5-year survival rate of $58 \%$ and a cure rate of $20 \%$ (LOE II; SOR A) (ROVC: 99\%)

11. Survival after systemic chemotherapy followed by surgery is superior to chemotherapy alone (LOE III; SOR B) (ROVC: 93\%)

12. Age, number and location of lesions and extrahepatic disease (if resectable) are not contraindications for surgery (LOE III; SOR C) (ROVC: $87 \%$ )

13. The aim of resection of liver metastases is to remove all macroscopic disease with clear (negative) margins (LOE II; SOR B) (ROVC: 100\%)

14. The ability to achieve clear margins (R0 resection) and assessment of the volume of healthy liver remnant should be determined by the radiologist and surgeon preoperatively (LOE III; SOR C) (ROVC: 100\%)

15. MDCT volumetry is considered as the method of choice to estimate remaining liver volume (LOE III; SOR C) (ROVC: 99\%)

16. Intraoperative US is the only method capable to detect the smallest liver metastases that may be missed by other imaging modalities (LOE III; SOR A) (ROVC: 93\%)

17. At one stage surgery, multiple resections can be performed, provided there is sufficient remnant liver $(>30 \%)$ and surgery is not too risky due to the location of the lesions. Other considerations must include the presence of questionably resectable extrahepatic disease and poor tumor biology (LOE IV; SOR A) (ROVC: 97\%)

18. There is a tendency towards segmental or wedge resections, instead of major hepatectomy (LOE III, SOR: B) (ROVC: 96\%)

\section{Perioperative chemotherapy}

\section{Background}

The role of perioperative chemotherapy in resectable CRC metastatic liver disease is unclear, particularly in case of a solitary, $<5 \mathrm{~cm}$ metastatic lesion. For resectable multiple metastatic disease of the liver, an EORTC trial using perioperative chemotherapy with FOLFOX (3 months before and 3 months after metastasectomy) showed superior progression-free survival (PFS) for the perioperative treatment group [33]. In addition, some more recent studies [34,35] have shown a survival benefit with perioperative chemotherapy. Although final survival data are still awaited, this approach represents a current standard with level 2 evidence. There is no evidence yet that adding a biologic to a cytotoxic doublet may improve outcome in resectable metastases, compared with a cytotoxic doublet alone. Intensification of induction chemotherapy is currently under investigation (FOLFOX beva/anti-endothelial growth factor receptor (anti-EGFR), FOLFOXIRI+/-beva/anti-EGFR). The optimal sequencing of chemotherapy in patients with resectable liver metastases (perioperative versus postoperative) was the subject of an ongoing NCI-sponsored trial (NSABP-C-11) but the study has been closed prematurely due to low accrual.

For patients with resectable disease and insufficient response on preoperative chemotherapy immediate metastasectomy may be considered. In case of progressive disease during preoperative chemotherapy, second line systemic chemotherapy should be administered. Alternatively, hepatic intra-arterial (HIA) chemotherapy in combination with systemic chemotherapy can be considered in very experienced centers.

\section{RECOMMENDATIONS}

19. For patients with primarily resectable lesions, treatment with FOLFOX for 3 months preoperatively, followed by resection, followed by 3-month FOLFOX treatment could be considered (LOE II; SOR A) (ROVC: $82 \%$ )

20. In case of solitary metastatic tumor $<5 \mathrm{~cm}$, use of pre-operative chemotherapy is unclear (LOE IV; SOR B) (ROVC: 97\%)

21.During preoperative treatment, a thorough evaluation for complete remission has to be performed, after 6 weeks of treatment (LOE III; SOR B) ROVC: 93\%)

22. If preoperative chemotherapy was not applied, in case of R0 resection, adjuvant chemotherapy, as in stage III colon cancer, for 6 months can be considered (LOE III; SOR A) (ROVC: 99\%)

23. Timing interval from chemotherapy to surgery should be 4-6 weeks, as also from surgery to adjuvant chemotherapy (LOE I; SOR A) (ROVC: 96\%)

24. For patients with resectable disease and insufficient response on preoperative chemotherapy immediate metastasectomy may be considered (LOE III; SOR B) (ROVC: 97\%)

25. In case of disease progression during preoperative chemotherapy second-line systemic chemotherapy should be administered (LOE II; SOR A) (ROVC: 94\%)

26. Alternative option for progressive disease is the use of HIA plus systemic chemotherapy, but only at very experienced institutions (LOE II; SOR B) (ROVC: $96 \%)$ 


\section{Surgery}

\section{Background}

An intraoperative staging is always recommended with the use of standard and contrast enhanced US. Intraoperative US may identify small solitary or multiple liver metastatic lesions, not preoperatively detected by other imaging modalities. In a recent study [36], 18\% additional lesions were identified in $44 \%$ of the patients. At surgery for the resection of CRC liver metastases, concomitant resection of the hepatic hilar lymph nodes is recommended for staging reasons [37]. Positive hilar lymph nodes can be found in up to $11.5 \%$ of patients, and may be associated with unresectability of the liver deposits in $28.6 \%$ of the cases [38]. Concomitant resection of involved lymph nodes may improve survival [37].

The standard procedure for liver metastases is a R0 resection of all lesions, sparing at the same time as much hepatic parenchyma as possible. For this reason, there is a tendency to shift from a typical liver lobectomy to multiple segmental or wedge excisions of metastatic lesions with adequate clear margin $[39,40]$.

In case of multiple resectable metastatic deposits the resection of which may not leave sufficiently functioning liver parenchyma, the two-stage surgery is recommended according to the following sequence: 1) 4-6 cycles of chemotherapy followed by imaging assessment; 2) surgery with wedge limited resections at the lobe which is to remain in situ complemented with ligation (PVL) or embolization of the portal vein (PVE) branch of the lobe to be removed; 3) optional chemotherapy and imaging reassessment after 4-6 weeks; 4) hepatectomy, provided that the remaining lobe is assessed as functionally sufficient; and 5) chemotherapy [41-44]. It has been suggested that chemotherapy, including targeted agents, at the interval between the two stages, does not impair liver degeneration after PVL $[45,46]$ and that omission of interval chemotherapy may result in progression of liver disease [47]. The choice of one- over two- stage surgery for resectable multiple metastatic lesions should be personalized according to tumor burden, anatomic location of deposits, anticipated functional sufficiency of hepatic remnant and presence of extrahepatic disease. It should be considered that resection of $>4$ lesions at one stage, is associated with less R0 resections and recurrence rates that exceed 58\% [48]. Presence of primary colorectal lesion and progression of the disease after the first stage preclude two-stage liver stage [44].

The in situ split procedure (PVL of the intended hepatic lobe to be resected and split of the hepatic parenchyma at the intended transection line) aims to induce rapid remnant liver parenchyma hypertrophy, allowing hepatic lobectomy at a second stage during the same admission. However, because the reported mortality is high and available evidence very limited the procedure cannot be recommended unless preformed in highly specialized centers and within the frame of research trials.

\section{Specific technical considerations}

According to a meta-analysis [49] and a more recent study [50], application of the Pringle maneuver (temporary clamping of the porta hepatis during hepatic resection) does not seem to have any effect on recurrence rate, the disease-free survival (DFS) or the overall survival (OS).

The laparoscopic approach for the resection of CRC liver metastases, has been applied in small series, by highly specialized surgical personnel. Immediate postoperative morbidity and mid-term survival are similar, while blood loss is less and length of hospital stay is shorter compared to the open approach [51]. There are also limited data on the robotic approach for the resection of CRC liver metastases from specialized centers [52].

\section{RECOMMENDATIONS}

27. After down-sizing or after complete response to preoperative chemotherapy, resection should include all initial sites of disease, if possible (LOE III; SOR A) (ROVC: 99\%)

28. Removal of some and not all lesions after preoperative chemotherapy is not recommended (LOE II; SOR B) (ROVC: 99\%)

29. In case of multiple bilateral lesions not amenable to one-stage surgery, two-stage surgery should be offered as follows: 1) 4-6 cycles of systemic chemotherapy and then imaging reassessment, followed by 2) surgery with small resections at the lobe to remain (if remnant is insufficient: PVL or PVE of the branch of the lobe to be resected), followed by 3 ) optionally systemic chemotherapy and imaging reassessment after 4-6 weeks, followed by 4) hepatectomy, followed by 5) systemic chemotherapy (LOE III, SOR B) (ROVC: 97\%)

30. Neither chemotherapy nor bevacizumab interfere with liver regeneration, when given at the interval between the two stages (LOE II, SOR B) (ROVC: $89 \%)$

31. Despite the potential liver damage, omission of interval chemotherapy between the two stages results in tumor cell proliferation (LOE III, SOR B) (ROVC: 92\%)

32. Choice of one- over two-stage surgery is personalized according to tumor burden, anatomical tumor location, potential R0 resection, sufficient liver remnant and extrahepatic disease (LOE III, SOR B) (ROVC: 100\%)

33. In case of more than 4 metastatic lesions, one-stage surgery is associated with less R0 resections and more recurrences (LOE III, SOR B) (ROVC: $85 \%$ )

34. Because mortality is high and available evidence very limited, the "in situ split" staged procedure cannot be recommended unless preformed in highly specialized centers and within the frame of research trials (LOE IV; SOR D) (ROVC: 100\%)

35. Due to lack of high level of evidence, the laparoscopic approach for the resection of hepatic metastases is not recommended, unless performed by a very experienced surgical team and within the context of clinical trials (LOE IV, SOR D) (ROVC: 97\%) 


\section{Ablation}

\section{Background}

In recent years, there is a tendency towards limited resections in combination with ablation of small lesions, instead of surgery alone for the treatment of multiple resectable metastatic lesions, aiming at preserving hepatic parenchyma [53]. Combination of surgery with ablation is indicated in the presence of increased metastatic burden, when complete surgical resection is not feasible and when ablation is applicable to small $<3 \mathrm{~cm}$ lesions not in the vicinity of major vessels. Oncological outcomes after surgery alone is superior to the combination of surgery with ablation, but the latter approach is applied to patients with increased metastatic burden [54-57]. In general, ablation either by radiofrequency (RFA) or microwaves (MWA) as a sole treatment is inferior to surgery, and apart as an adjunct to surgery, is reserved for patients unfit to undergo surgery or as a bridge to surgery [29].

There has been a debate whether a solitary liver metastasis could be treated by resection or ablation with the use of radiofrequency. According to a meta-analysis [58] and some additional comparative studies [59-61] resection of the solitary metastatic lesion, particularly when $>3 \mathrm{~cm}$, is associated with better oncological outcomes (OS and DFS) compared to RFA. For hepatic metastatic lesions $<3 \mathrm{~cm}$ both modalities offer similar OS and DFS [59].

\section{RECOMMENDATIONS}

36. Ablation is generally inferior to resection. However, it can be used, preferably with the use of RFA or MWA: 1) in patients unfit for surgery; or 2) as bridge to resection; or 3 ) in combination with resection (if liver remnant is not considered functionally sufficient) (LOE IV; SOR D) (ROVC: 100\%)

37. Surgery combined with ablation is indicated: 1) in case of increased metastatic burden; 2) when complete resection is not feasible; and 3) when small lesions $(<3 \mathrm{~cm})$ to be ablated are not in the vicinity of major vessels (LOE II, SOR B) (ROVC: 99\%)

38. Surgery, compared to surgery combined with ablation, offers better oncological outcomes, although the latter approach is reserved for patients with greater tumor burden (LOE II, SOR B) (ROVC: 99\%)

\section{Adjuvant chemotherapy}

\section{Background}

The role of adjuvant chemotherapy after R0 metastasectomy is still unclear. Also, unclear is the role and efficacy of chemotherapeutic regimes including targeting agents. Underpowered trials with 5-FU and levamizole (LV) or HIA with FUDR+ systemic chemotherapy with 5-FU+LV have shown some advantage, although no study has shown a clearly significant survival benefit $[62,63]$. Nevertheless, postoperative adjuvant systemic chemotherapy is recommended, as in the case of stage III colon cancer, in Europe and USA, despite lack of level 1 or 2 evidence. In an ongoing phase II/III trial in Japan, adjuvant FOLFOX6 was compared to surgery alone [64].

Currently the value of bevacizumab, in addition to adjuvant capecitabine (XEL) and oxaliplatin (XELOX), after liver metastasectomy, is being investigated in the Netherlands. Another trial (NSABP C-09), comparing adjuvant systemic oxaliplatin plus XEL alone or with HIA FUDR, has been closed prematurely due to the low accrual.

\section{RECOMMENDATION}

39. There is no substantial evidence that adjuvant chemotherapy after R0 hepatic metastasectomy offers to oncological outcomes (LOE IV, SOR B) (ROVC: 91\%)

\section{Other adjuvant therapeutic modalities}

\section{Background}

Initially, there has been evidence that administration of HIA in addition to systemic chemotherapy after R0 resection of liver metastasis offers better 2-year survival and longer PFS than systemic chemotherapy alone $[65,66]$. However, a systematic review [67] showed that HIA has no additional benefit to adjuvant systemic chemotherapy on survival.

\section{RECOMMENDATION}

40. HIA as an adjunctive modality after R0 hepatic metastasectomy is of no benefit (LOE III, SOR B) (ROVC: 96\%)

\section{Immediate postoperative outcomes}

Provided that patients are treated in high volume centers, with highly specialized and experienced personnel and have been subjected to thorough preoperative assessment, immediate postoperative morbidity and mortality are low. Morbidity and mortality depend on several parameters, which include extent of perioperative chemotherapy, amount of resected hepatic parenchyma, loss of blood and needs for blood transfusion [68-70].

Postoperative liver failure is seen in approximately $10 \%$ of cases and depends on the functional adequacy of the remaining hepatic parenchyma. Postoperative liver failure has a remarkable impact on postoperative mortality [69]. 


\section{Management of resectable lung metastases}

\section{Background}

Patients with limited lung metastases should be subjected to surgical R0 resection. Resection of lung metastases can be performed by thoracoscopy with equal or even better shortterm results than after thoracotomy. The 5 -year survival rate after R0 resection is $35-50 \%$, and depends on multiplicity and size of metastatic lesions, status of hilar or mediastinal lymph nodes, and history of liver metastasis [71-74]. The 5 -year recurrence rate after the first metastasectomy is 35\% by thoracoscopy and $21 \%$ by thoracotomy [74].

Despite the lack of data regarding perioperative treatment, an approach similar to the management of resectable liver metastases should be considered. A FOLFOX regimen is recommended for 3 months prior and 3 months after resection mainly based on the data from stage III disease and those for the perioperative treatment of after liver resection [33]. Alternatively, an initial resection, without perioperative treatment, followed by postoperative chemotherapy can be applied.

\section{RECOMMENDATIONS}

41. Successful resection of lung metastases, offers a 5-year survival rate in almost one third of patients (LOE III; SOR B) (ROVC: 100\%)

42. Peri- or post- operative chemotherapy is recommended (LOE II; SOR A) (ROVC: 95\%)

\section{Treatment of advanced metastatic disease (Fig. 2)}

The aim of the first-line treatment depends on the clinical presentation and biology of the tumor (metastases limited to liver or lung or both, or peritoneum; dynamics of progression; symptoms) and patient factors (comorbidities, age, potential to undergo secondary resection). In case of major response to induction chemotherapy of liver, lung (or even peritoneal) R0/R1 resection can result

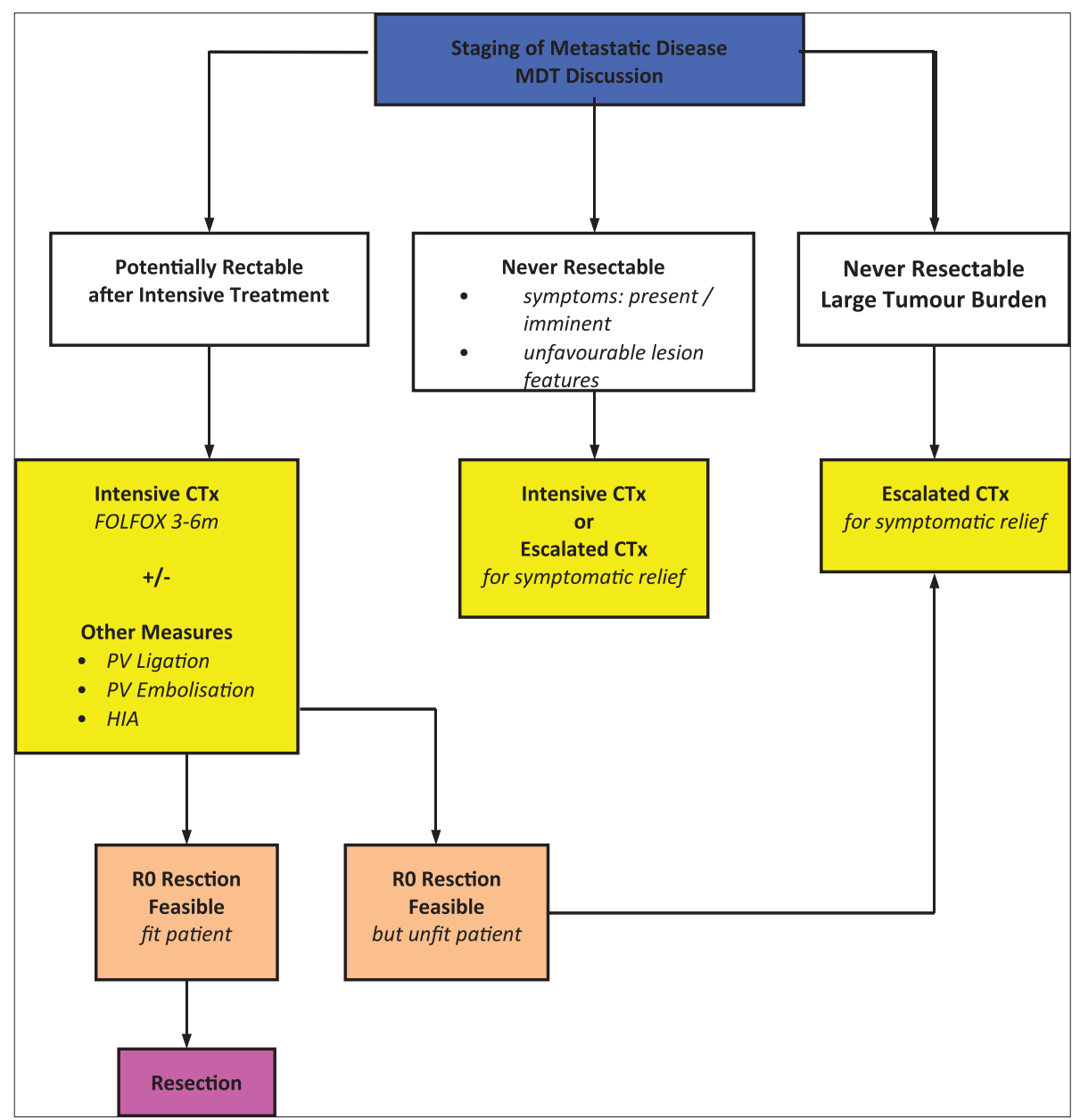

Figure 2 Strategy and treatment algorithm of metachronous advanced metastases (liver $+/$ - lungs)

$M D T$, multi-disciplinary team; CTx, chemotherapy; PV, portal vein; HAI, hepatic arterial infusion chemotherapy; FOLOX, 5-fluoro-uracil plus oxaliplatin 
in long-term survival and potentially cure in a minority of patients. With this respect, patients can be individually categorized into the following three clinical groups, by parameters describing localization and extent of disease, tumor dynamics, co-morbidities, potential of the patient to tolerate chemotherapy and surgical treatment: 1) liver ( \pm lung) metastases only, which may become resectable after induction chemotherapy \pm limited/localized metastases to other sites, and subject physically able to undergo major surgery (biological age, heart/lung condition); 2) multiple metastases with rapid progression, tumor-related symptoms and risk of rapid deterioration, with co-morbidity allowing aggressive treatment; and 3) unresectable metastases - never suitable for resection, without major symptoms or risk of rapid deterioration, or with severe co-morbidity, precluding surgery and/or intensive systemic treatment.

\section{Molecular factors}

With the exception of RAS mutation, which precludes patients from treatment with anti-EGFR antibodies, there is no other prognostic/predictive molecular marker, relevant to routine first-line treatment, which affects decision outside clinical trials in advanced metastatic disease [75-78].

\section{Clinical factors}

\section{Background}

Although never prospectively proven, the achievement of a disease-free status after chemotherapy and surgery, is the only mean to give the potential for long-term survival or cure, in an otherwise incurable/palliative situation. For this aim, the most active induction chemotherapy which is able to induce downsizing as much as possible in as many patients as possible, should be selected for group I. Furthermore, downsizing after chemotherapy is a marker of favorable tumor behavior [42,79-82]. A chemotherapeutic scheme of 5-FU, oxaliplatin and irinotecan succeeded to convert initially unresectable to resectable liver metastases, in a limited cohort of patients [83]. For the intermediate group II, the aim is a rapid regression of metastases, particularly in cases of imminent tumor associated complications. An escalation strategy, namely single agent chemotherapy followed by combination, could be hazardous because, at the time of switch to a more effective second-line treatment, it might be "too little - too late" for a favorable outcome. Patients of group iii are treated mostly with a palliative intent. Therefore, an escalation strategy seems appropriate. However, a small percentage of these patients with excellent responses might also become candidates for secondary surgery with further escalation [84].
44. Patients with: 1) co-morbidities and unfit to undergo surgery; 2) multiple, rapidly progressing, metastatic deposits; and 3) severe symptomatic metastases, are amenable to palliative treatment (LOE IV, SOR B) (ROVC: 100\%)

45. Aggressive chemotherapy should be personalized and aim to reduce metastatic tumor burden to alleviate symptoms (LOE III, SOR C) (ROVC: 95\%)

\section{Choice of chemotherapeutic regimen}

\section{Background}

Available chemotherapeutic agents are fluoropyrimidines (5-FU modulated by folinic acid [FA], or XEL), irinotecan and oxaliplatin. XEL can be safely substituted by 5-FU/FA in combination with oxaliplatin (FOLFOX) and in combination with irinotecan (FOLFIRI), after the necessary dose adjustment of both drugs. However, FOLFIRI should be the preferred option over XELIRI as it is associated with less toxicity from the gastrointestinal tract [85].

Monoclonal antibodies are the vascular endothelial growth factor (VEGF) targeting bevacizumab and the antiEGFR antibodies cetuximab and panitumumab. Anti-EGFRantibodies have no activity in RAS mutant tumors. The combination of XEL, oxaliplatin with cetuximab, and also panitumumab, seem to have no additional benefit over XEL and oxaliplatin alone and should be avoided at present [86].

Standard combination chemotherapy regimens comprising $5-\mathrm{FU} / \mathrm{LV}$ in combination with either irinotecan, typically FOLFIRI, or oxaliplatin (FOLFOX) have been reported to facilitate the resection of $7-40 \%$ of patients with initially unresectable metastases depending upon the initial selection of patients [33]. However, 75-80\% of these patients experience cancer relapse within 2 years of resection. Data emerging from randomized trials suggest that the addition of a targeted agent (bevacizumab or cetuximab) or even scarce data of phase II trials on the combination with a third cytotoxic plus or minus a targeted agent, might be even more effective, although concerns about toxicity limit the use of this triplet to highly selected cases. The combination of a chemo-doublet plus cetuximab has led to higher resection rates (although still low in absolute numbers) in patients with liver limited unresectable metastatic RAS wild-type (wt) CRC. The combination of FOLFOX/ cetuximab and FOLFIRI/cetuximab has led to similar response rates and resection rates in $R A S$ wt tumors $[87,88]$.

The combination of a fluoropyrimidine/oxaliplatin/ bevacizumab has led to a non-significant trend in an increased resection rate compared with the chemo-backbone alone, although no increase in response rate was shown [89]. In a more recent study [90], it was shown that backbone chemotherapy combined with bevacizumab is associated with increased 
response and resectability rates and improved survival. There are no data available from randomized studies comparing a chemo-doublet plus bevacizumab with a chemo-doublet plus cetuximab.

Limited data exist concerning the three-drug combination FOLFOXIRI and the possibility to use it as an alternative option to FOLFIRI/FOLFOX + cetuximab with probably more toxicity, especially when targeting agents such as cetuximab are not available or are contraindicated [91,92]. Possible chemotherapeutic regimens, also including targeting agents are listed in Table 2.

First-line regimens depend on the chosen treatment strategy. For potentially resectable and/or symptomatic disease, first line treatment should ideally be a chemotherapy doublet in combination with a monoclonal antibody or a triplet. If tumor shrinkage is desirable, treatment with FOLFIRI and cetuximab for RAS wt or FOLFOXIRI should be considered [93]. Firstline treatment with monotherapy [94] or doublet (either chemotherapy or chemotherapy with monoclonal antibodies) could be a valid option for patients, for whom a secondary resection is not feasible, and who have no symptoms or risk for deterioration of the disease [95].

Selected induction chemotherapy should be given for at least 8 weeks, and first re-assessment is performed, in order to avoid unnecessary chemotherapy application in case of early progression $[96,97]$. If the treatment aim is pure palliation, the timing of first evaluation is of less importance, and an interval of 12 weeks might be more appropriate [98]. The overall induction treatment duration depends on the treatment aim. If secondary surgery is attempted, induction chemotherapy should be continued until R0 resectability can be achieved, with the first evaluation after 8 weeks, as mentioned above. If the chosen chemotherapeutic regimen continuous to be active, a 4-month duration of treatment is recommended; if resectability is still not achievable, duration of treatment can be extended to 6 months. Further treatment with the same regimen is not recommended [98].

If the aim of secondary resection cannot be achieved, as well as in patients where resection is not the aim of treatment, this should be continued according to the individual's situation, patients' needs, cumulative toxicity, particularly with oxaliplatin and aggressiveness of the disease [99].

In most patients, survival is not significantly affected, if first-line treatment is not given continuously until progression, particularly in case of oxaliplatin discontinuation because of cumulative neurotoxicity [100]. Drug and treatment "holidays" are acceptable options in selected patients, after a substantial initial period of treatment $[100,101]$. Recently presented data support that de-escalation of chemotherapy combined with continuation of bevacizumab after induction treatment with XELOX+bevacizumab leed to significant benefit in PFS, but with limited impact in median OS [95].

The selection of the subsequent treatment lines should be based on the type of first-line treatment, response and/or PFS to first-line treatment, patient's performance status (PS) and preferences and taking into consideration the cost of treatment. New agents such as aflibercept (in second-line treatment) or regorafenib ( $\geq$ third-line treatment) could be considered in specific patient subpopulations.

\section{RECOMMENDATIONS}

46. Aggressive treatment regiments are FOLFOXIRI (LOE II; SOR C), FOLFIRI (LOE I; SOR B) and FOLFOX (LOE I; SOR B) and could be used alone or with the addition of anti-EGFR antibodies (RAS wt) or bevacizumab (LOE II, SOR B) (ROVC: 100\%)

47. Duration of induction treatment may exceed 6 months, in case of favorable response (LOE II; SOR B) (ROVC: $84 \%)$

48. RAS mutation precludes patients from treatment with anti-EGFR antibodies at the preoperative settings (LOE II, SOR B) (ROVC: 100\%)

49. Alternative regimes, in patients with progressive metastatic disease are mXELIRI+/-bevacizumab or cetuximab (RAS wt) (LOE II; SOR C), or FOLFOX + panitumumab/ cetuximab (RAS wt) (LOE II; SOR B) (ROVC: $100 \%$ )

50. For RAS wt tumors, induction treatment with FOLFIRI + cetuximab or FOLFOX + anti-EGFR antibodies appears to be more effective in terms of major tumor shrinkage and secondary resectability, than bevacizumab based combinations, for which less data are available (LOE II; SOR B) (ROVC: 89\%)

51. FOLFOXIRI should be considered as a treatment option especially for patients with RAS mutant tumors (LOE II; SOR C) (ROVC: 96\%)

52. For palliation: i) fluoropyrimidine \pm bevacizumab (sequential treatment) (LOE II; SOR B); or ii) doublets chemotherapy (LOE I; SOR A); or iii) doublets chemotherapy + anti-EGFR (RAS wt) (LOE II; SOR B) can be given (ROVC: $100 \%$ )

\section{Additional upfront measures}

\section{Background}

HIA can be used to downsize hepatic metastases and render them resectable, with improvement in survival rates [102,103]. This modality can be applied either as a first-line neo-adjuvant treatment in combination with systemic chemotherapy [104], or as a second-line approach in combination with chemotherapy when first-line systemic chemotherapy has failed to downsize metastatic lesions. Still, effectiveness of this modality remains questionable $[105,106]$.

The initial chemotherapeutic regimen contained floxuridine and dexamethasone; the latter was given for the prevention of hepatic and biliary toxicity [107-110]. Other combined agents, such as 5-FU and leucovorin with or without oxaliplatin, have been given to reduce hepato-biliary toxicity and improve oncological outcomes, but data are limited and evidence is low at present $[105,110-114]$. HIA chemotherapy with novel agents 
is tested, aiming at improvement of oncological outcomes. It is evident that more trials are needed to assess any additional survival benefit of HIA to systemic chemotherapy, including new chemotherapeutic regimens.

\section{RECOMMENDATIONS}

53. The rationale of HIA modalities is that: 1) hepatic metastases are primarily supplied by branches of the hepatic artery; and 2) larger quantities of the therapeutic agent in use is delivered to tumor site and less to the systemic circulation, thus reducing the danger of systemic side effects (LOE III; SOR C) (ROVC: $100 \%$ )

54. HIA chemotherapy should be practiced in highly specialized centers (LOE II, SOR B) (ROA: 100\%)

55. HIA chemotherapy is administered through surgically placed ports or implantable continuous infusion pumps (LOE II, SOR B) (ROVC: 100\%)

56. The most common chemotherapeutic scheme in use is floxuridine with dexamethasone. The latter agent is given to reduce the risk of toxic injury to the biliary tract (LOE II, SOR B) (ROVC: 94\%)

57. Side effects of HIA chemotherapy with floxuridine and dexamethasone are intestinal mucosa ulceration and diarrhea, biliary toxicity, and hepatic parenchyma toxicity (LOE II, SOR B) (ROVC: 100\%)

58. HIA chemotherapy is usually combined with systemic chemotherapy (LOE II, SOR B) (ROVC: 96\%)

59. Evidence on the use of other chemotherapeutic regimens (5-FU with leucovorin, or oxaliplatin) is limited (LOE IV; SOR D) (ROVC: 95\%)

60. Indications of HIA chemotherapy combined with systemic chemotherapy are: 1) failure of first-line systemic chemotherapy to convert unresectable liver metastases to resectable; 2) as a first-line approach for initially unresectable disease; and 3) as adjuvant approach after R0 resection of liver metastases (LOE IV; SOR D) (ROVC: 90\%)

61. Although HIA chemotherapy may offer a longer PFS, the approach does not improve OS (LOE II; SOR B) (ROVC: 98\%)

\section{Surgery}

\section{Background}

Surgery can be performed safely after 4 weeks from the last cycle of induction chemotherapy with or without cetuximab, and 5-8 weeks following chemotherapy with bevacizumab. A reasonable time interval allows liver function to recover $[70,115]$. Resection of the metastases should be performed as soon as metastases become resectable, since unnecessary prolonged administration of chemotherapy may lead to a higher postoperative morbidity. A R0 resection should be attempted including all initial sites of disease if possible, even in the case of complete clinical response, because "expectant policy" and deferral of surgery is associated with increased recurrence rates $[116,117]$. In order to preserve functional hepatic parenchyma, resection, either in the form of typical lobectomy or of multiple segmental and wedge resections, lesions $<3 \mathrm{~cm}$ can be thermally ablated with the use of RFA or MWA, and with low added morbidity and mortality. Ablation of lesions $>3 \mathrm{~cm}$ is associated with increased recurrence rates [56,118-123]. MWA carries the advantages of less risk of charring, less incidence of "heat sink" effect and ability to ablate larger lesions as compared to RFA. The disadvantage of MWA is the increased risk of thermal injury to adjacent structures [122,124,125].

In case of increased but resectable metastatic burden and increased risk of liver failure after one stage resection, a twostage surgery can be applied (first stage: wedge resections of the lobe to remain and PVL or PVE of the branch of the lobe to be resected; second stage: hepatic resection). PVE and PVL show similar hypertrophy of the remnant hepatic lobe [126]. According to a meta-analysis including 1088 patients from 37 studies [127] and a more recent study [128], PVE is a safe and effective procedure that induces sufficient liver hypertrophy of the remnant liver and prevents postoperative liver failure.

A recently described alternative approach to induce rapid hypertrophy of the left lobe and enable extensive right lobectomy is the "in situ split" procedure combined with right PVE or PVL at a first stage and extensive right lobectomy at a second stage, at the same admission. There is little evidence on this approach, which is associated with mortality of $12 \%$ [129].

Portal vein chemotherapy at the immediate postoperative period, after R0 resection of liver metastases does not seem to be of any additional oncological benefit over curative surgery alone [130]. The postoperative morbidity is more related to the duration of the chemotherapy, than to the type of chemotherapy that is administered, although oxaliplatin and irinotecan may cause different histological changes in liver parenchyma, oxaliplatin is related to sinusoidal liver lesions and irinotecan to steatohepatitis [131-133].

\section{RECOMMENDATIONS}

62. Surgery can be performed safely after 4 weeks from the last cycle of chemotherapy and 5-8 weeks following bevacizumab containing treatment (LOE IV; SOR C) (ROVC: 96\%)

63. If possible, all residual tumor lesions should be resected. Additional measures like prior PVE to enable resection of otherwise non-resectable lesions, or ablative modalities (RFA) might be used (LOE IV, SOR C) (ROVC: 100\%)

64. Lesions with complete regression mostly contain residual viable tumors cells. However, it is not clear whether all initially involved sites should be resected irrespective of response or whether only visible residual (pre- or intra- operative imaging) lesions should be resected (LOE III, SOR D) (ROVC: 87\%) 


\section{Non-surgical management of liver metastatic disease}

Non-surgical management of liver metastasis should not be pursued instead of resection of metastasis, but only attempted in case of unresectable liver disease [134,135]. Patients not suitable for surgery, due to either bulky lesions, or unfitness, or presence of non-resectable extrahepatic metastases, should be treated upfront with systemic chemotherapy. Patients showing progression of the disease after chemotherapy, or presenting toxicity from systemic therapy that limits chemotherapeutic options, are potential candidates for palliative, ablative or regional chemotherapeutic interventions.

\section{Ablative techniques}

\section{Background}

RFA. Patients whose tumors have been downsized by chemotherapy but remain still unresectable, can be subjected to ablative therapy. RFA is accepted as preferable to other ablative techniques for treating colorectal metastases. Factors determining success are lesion size, the number of lesions and location [136]. Ablation should be reserved for patients with a limited number of smaller tumors. Local recurrence is significantly higher for $>3-5$ colorectal metastases, while prognosis is worse when more than five metastases are present at the time of ablation $[118,123]$. Larger tumors may be treated with a combination of ablation and arterial embolization or chemo-embolization $[137,138]$.

RFA may be performed intraoperatively, laparoscopically, or percutaneously. The percutaneous approach is associated with the least procedural risk and may be performed under local anesthesia, but is less effective. Percutaneous RFA should be considered as a primary treatment option for patients with unresectable hepatic tumors or conditions that prohibit general anesthesia or abdominal surgery [139]. Laparoscopic RFA has been also attempted with low local failure rates, a median recurrence free survival of 15 months, and mean actuarial survival of approximately 4 years [140].

Other ablative modalities. Other palliative modalities of liver metastatic disease are: 1) external radiation. Use of proton-based instead of stereotactic body radiotherapy for solitary unresectable liver metastatic lesions spares considerably liver parenchyma and prevents injury to adjacent structures [141-145]; 2) radiochemoembolization. Combination of chemoembolization (mitomycin, cisplatin and doxorubicin) with radioembolization induces a shortterm reduction in tumor size [146], and 3) portal vein chemotherapy. These modalities are in use in highly specialized centers and applied in selected patients. At present, evidence is limited.

\section{RECOMMENDATIONS}

65. Indications for ablation techniques to control colorectal metastatic disease are poorly defined (ROVC: 90\%)

66. Ablation techniques can be applied as an adjunct to hepatic resection, to preserve liver parenchyma (LOE II; SOR B) (ROVC: 97\%)

67. Ablation techniques can be recommended as a first-line treatment for small metastatic lesions at appropriate locations (not in the vicinity of large vessels), if surgical resection is not considered safe or contraindicated (LOE II; SOR B) (ROVC: 99\%)

68. There is poor evidence to support ablation of liver metastases as a first-line treatment instead of surgical resection (LOE III, SOR D) (ROVC: 97\%)

69. Application of ablation therapies are limited by the: 1) features of the lesions (size, location, multiplicity); 2) substantial morbidity; and iii) high recurrence rates (LOE II; SOR A) (ROVC: 97\%)

70. Factors affecting recurrence after RFA are tumors $>3 \mathrm{~cm}$, tumor proximity to large vessels and percutaneous instead of surgical approach (LOE II; SOR B) (ROVC: 96\%)

\section{Selective internal radiation therapy (SIRT)}

\section{Background}

SIRT with Yttrium-90 of liver metastases from primary CRC often results in a high rate of tumor regression. All patients indicated for a SIRT must not have widespread metastases, which are ruled out by PET-CT or whole body CT/MRI. Current evidence on the safety of SIRT for nonresectable colorectal metastases in the liver is adequate. For patients who have previously been treated with chemotherapy, there is evidence that SIRT can achieve control of hepatic metastases, but the evidence of its effects on survival and on quality of life is inadequate (NICE consultation document 2011).

The response rate based only on changes in tumor volume according to the CT (RECIST) is often poor. However, after SIRT there is a significant decrease of tumor markers and FDG-uptake, proving that tumor nodules are no longer viable. Patient selection is also a key issue because there are considerations that a subgroup of patients with huge metastases or pre-existing extrahepatic manifestations seem to benefit less from this therapeutic modality [147]. There is no evidence that the modality can be applied as a first-line treatment in combination with systemic chemotherapy for unresectable liver metastases [148-151]. 


\section{RECOMMENDATIONS}

71. Yttrium-90 hepatic trans-arterial embolization could be considered as a palliative measure in patients with liver metastases only, who fail to respond to systemic chemotherapy (LOE III, SOR C) (ROVC: 96\%)

72. There is no substantial evidence to support the use of Yttrium-90 hepatic trans-arterial embolization as: 1) second-line approach when first-line chemotherapy has failed to convert unresectable liver metastases to resectable; and 2) first-line treatment in initially unresectable liver metastases (LOE IV; SOR D) (ROVC: 100\%)

\section{Transarterial chemoembolization (TACE)}

\section{Background}

TACE using irinotecan-loaded beads is safe and effective in the treatment of patients following failure of standard systemic chemotherapy. Patients may receive repeat embolizations (max $100 \mathrm{mg}$ per session). The technique is associated with minimal complication rate and acceptable tumor response [152,153]. Neither the number of liver lesions, the size of liver lesions or the extent of liver replacement ( $<25 \%$ vs. $>25 \%$ ) are predictors of OS. TACE may also achieve downsizing of metastases, so that they can be treated by thermal ablation, at a following stage [154]. Treatment by TACE shows a significant benefit for patients who have failed first- and second-line systematic chemotherapy, and is potentially a more effective approach when compared to the historical response rates after third- or fourth-line systemic chemotherapy. The fact that substantial extrahepatic progression is often observed after regional treatment for liver metastases, further suggests that systemic chemotherapy should be added to chemoembolization.

\section{RECOMMENDATION}

73. There is no substantial evidence to support TACE (release or irinotecan - DEBIRI) as a palliative measure for unresectable, isolated liver metastases (LOE III; SOR D) (ROVC: 90\%)

\section{Synchronous primary and metastatic disease}

\section{General considerations}

\section{Background}

Synchronous primary CRC and metastatic disease seems to be associated with worse prognosis compared to metachronous metastatic disease [28,155-159], although there are reports supporting the view that synchronous and metachronous metastatic disease share similar prognosis [25,160-163]. Prognostic factors of synchronous metastatic disease are primary tumor differentiation and lymph node status, presence of complications from the primary lesions, number and size of metastatic lesions, potential of curative surgery of both primary and metastatic disease, presence of extrahepatic metastatic disease and the level of serum CEA [164].

After MDT discussion and continuous at every stage-interval assessment, as well as personalization of treatment, planning, timing and sequencing of therapeutic modalities, namely chemotherapy and intervention for primary and secondary disease, are critical for the best oncological outcome. The best outcomes are achieved after R0 resection of both primary and metastatic disease. Resection of the primary lesion leaving intact metastatic disease, does not improve oncologic outcome. In the presence of unresectable metastatic disease, primary lesion is resected only for cure of complications [165-168].

\section{RECOMMENDATIONS}

74. Presence of synchronous disease seems to be associated with worse prognosis, although opposite views, namely similar prognosis to metachronous disease, are being expressed (LOE III, SOR B) (ROVC: 93\%)

75. Planning, timing, and sequencing of interventions, according to the MDT discussion, are critical (LOE III, SOR A) (ROVC: 100\%)

76. $\mathrm{R} 0$ resection is imperative for both primary lesion and metastatic disease (LOE III, SOR A) (ROVC: $100 \%)$

77. Resection of the primary lesion leaving metastatic disease intact, does not improve survival, and is not recommended, unless it is symptomatic (LOE IV, SOR) (ROVC: 92\%)

78. Survival after R0 resection of both primary lesion and metastatic disease is $40-58 \%$ (LOE II, SOR B) (ROVC: 96\%)

\section{Upfront systemic chemotherapy}

Upfront systematic chemotherapy is indicated in all cases. The most common schemes in use are FOLFOX and FOLFIRI [169]. The addition of targeting agents (i.e. bevacizumab) increases the risk of bleeding or perforation at the site of primary lesion [170]. Response to upfront chemotherapy is a prognostic marker for outcomes and a tool of patient's selection for further treatment, preventing unnecessary non-therapeutic operations, in case of lack of response. Most hepatic metastatic lesions reduce in size or remain stable, and this translates to reduced recurrence rates, and better survival rates [33,169,171-174]. In general, upfront chemotherapy is considered safe for the intact primary lesion, unless complications are pending or present [175-177]. Also, upfront chemotherapy and delay of resection of rectal cancer does not impair oncological outcomes and might also prevent local recurrence [178]. Given the fact that mostly primary but also metastatic lesions may disappear as a result of favorable response to chemotherapy, it is recommended that the site of the lesions to be marked (Indian ink for the primary; metallic coils for the metastatic lesions) prior to treatment initiation [179]. 


\section{Surgical approaches}

There are three approaches to the sequence of surgical procedures: 1) simultaneous resection of both primary and metastatic disease; 2) surgery for the primary lesion first; and 3) surgery for the metastatic (hepatic) lesions. Sequencing of procedures is personalized. Priority is given to the most pressing component of the disease, attempting to minimization of morbidity and mortality rate.

Simultaneous resection of both primary lesion and metastatic disease carries less morbidity, similar mortality and less length of hospital stay as compared to staged approach, provided that colorectal surgery is straight forward and hepatic resection is limited to segmental (up to four segments) or wedge excisions $[175,180-186]$. When a major hepatectomy is required, simultaneous surgery is associated with worse short-term outcomes $[187,188]$. When major surgery for either the primary lesion (i.e. low anterior resection of rectum, abdominoperineal resection of rectum, subtotal colectomy) or the hepatic metastatic disease (i.e. right lobectomy, extended liver resection), a staged approach is recommended [184]. It has been suggested that when the duration of simultaneous resection is anticipated to be $<6 \mathrm{~h}$ and expected morbidity is acceptable, a simultaneous resection must be chosen. Otherwise, a staged approach is recommended [189].

At the staged approach either colorectal or hepatic surgery is performed at the first stage. Colorectal surgery "first" is chosen in case of perceived complications at the site of the primary lesion (perforation, bleeding obstruction), followed by systemic chemotherapy, followed by resection of liver metastases $[180,185,186,188,190]$. Liver surgery "first" is the approach of choice, when progression of metastatic disease to become unresectable is imminent. After systemic chemotherapy and resection of metastatic disease, chemotherapy, alone or in combination with radiotherapy in case of rectal cancer, is given [191]. Resection of the primary lesion follows [175,192,193].

In selected cases and in experienced centers, a laparoscopic approach can be applied both for the resection of primary and hepatic metastases, either by the one- or two- stage approach [194].

\section{Location of the primary lesion}

The approach of synchronous primary and metastatic colorectal disease is also personalized according to the location of the primary tumor, as follows:

\section{Synchronous metastatic colon cancer (Fig. 3)}

Initially resectable synchronous disease should be treated preoperatively with FOLFOX for 3 months, then by resection of the primary tumor and of metastases, either staged or synchronous, followed by postoperative administration of FOLFOX for 3 months. a) Symptomatic primary disease: In case of symptomatic primary and resectable systemic disease, resection of the primary tumor, and metastases if possible, should be performed upfront, followed by "adjuvant" chemotherapy for 6 months. In case of symptomatic primary and unresectable systemic disease, resection of the primary tumor should be performed, followed by induction chemotherapy and further treatment according to response.

b) Asymptomatic primary disease: In case of unresectable systemic disease, there is no benefit from upfront surgery for a non-symptomatic primary tumor. Instead, upfront systemic chemotherapy is recommended. In case of secondary resectability of metastatic disease after induction chemotherapy, resection of the primary tumor and metastases either staged or synchronous, should be performed. In case of insufficient response of liver metastases to induction chemotherapy, surgical resection may not be performed, as tumor R0 resection does not improve survival.

\section{Synchronous rectal tumor and metastatic disease (Fig. 4)}

In case of a rectal tumor with synchronous metastatic disease, treatment should be personalized. There are the following options:

a) Non-symptomatic early or intermediate rectal tumor: chemotherapy followed by assessment of the response of the metastatic lesion. If response is favorable and resection of metastatic disease is feasible, surgery should be considered: 1) primary tumor surgery first, followed by metastatic disease resection at a second stage; 2) metastatic disease resection first, followed by resection of primary disease at a second stage; 3 ) one stage resection of primary and metastatic disease. If response of metastatic disease is not favorable and primary tumor is asymptomatic, no surgery is required.

b) Symptomatic advanced rectal tumor: Chemoradiotherapy followed by chemotherapy at the resting period and assessment of the response of both the primary and the metastatic lesion. Depending on the response, the following therapeutic measures are taken: If response of both primary and metastatic disease is favorable, with anticipated R0 resection of both: 1) resection of primary and metastatic disease at one stage; 2) metastatic disease resection first, followed by resection of primary disease at a second stage; 3) primary tumor surgery first, followed be metastatic disease resection at a second stage. If response of metastatic disease is not favorable and primary tumor becomes asymptomatic, no surgery is required. Also, if R0 resection of the primary lesion is not feasible no surgery is required. In both latter cases, palliative measures can be undertaken. If response of metastatic disease is not favorable and primary tumor is asymptomatic no surgery is required. Also, if R0 resection of the primary lesion is not feasible, no surgery is required. In both latter cases, palliative measures can be undertaken. 


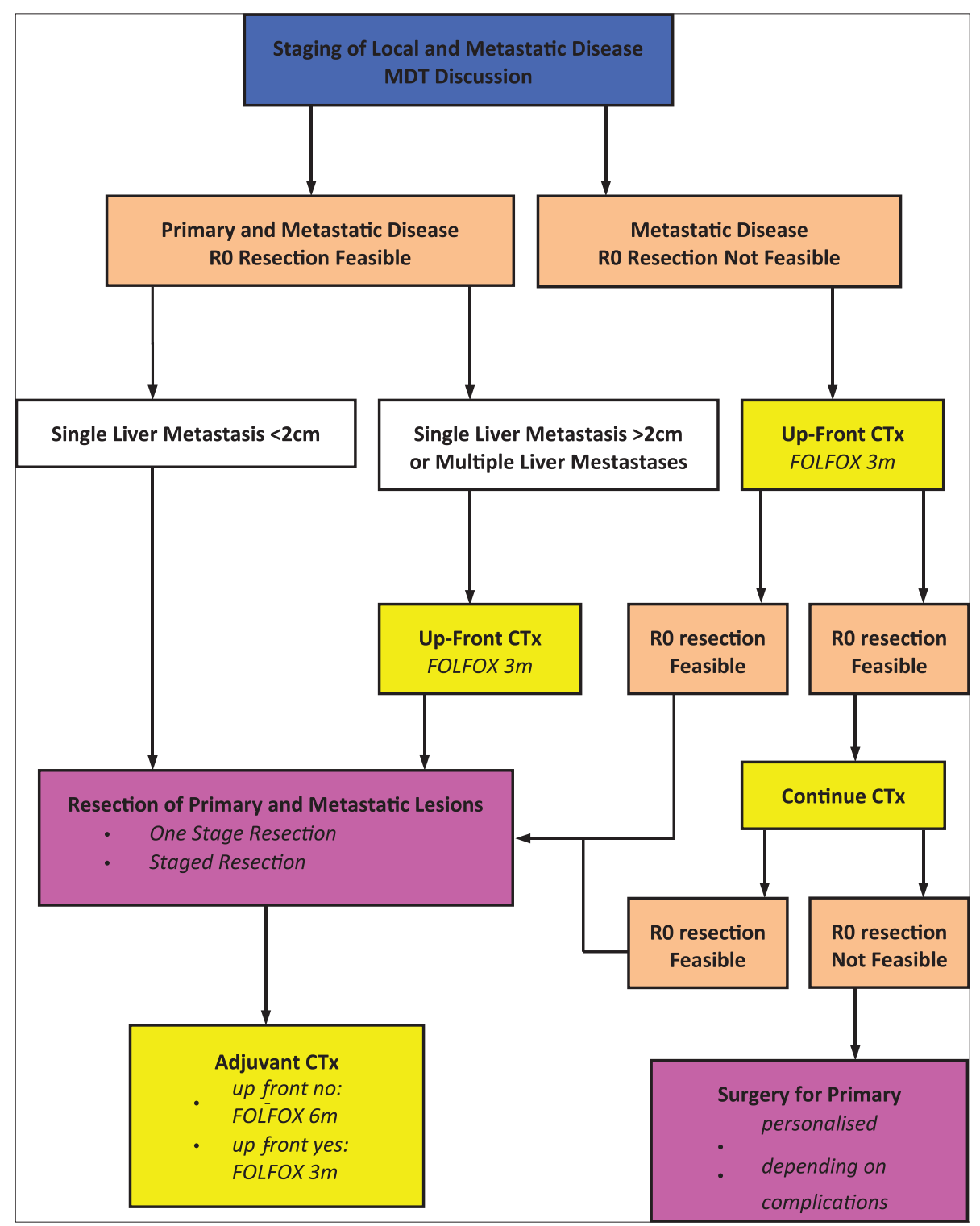

Figure 3 Strategy and treatment algorithm of synchronous colon cancer and metastases MDT, multi-disciplinary team; CTx, chemotherapy; FOLOX, 5-fluoro-uracil plus oxaliplatin

\section{Prognosis of metastatic liver disease}

3- and 5-year OS rates are around 50\% and 30-47\% respectively, after curative treatment of hepatic metastatic disease (R0 resection), while median survival extends to 50 months. Predictors of adverse oncological outcomes are female gender, primary disease with advanced $\mathrm{T}$ and $\mathrm{N}$ stage, number of hepatic metastatic lesions $>4$, size of largest lesion $>5 \mathrm{~cm}$, bilobar disease, extrahepatic disease, serum CEA $>5 \mathrm{ng} / \mathrm{mL}$ and serum CA19-9 >37 U/mL [38,59,195-202]. Presence of positive lymph nodes at the hepatic hilum has an adverse effect on oncological outcomes [38]. Also, presence of C-reactive protein polymorphism and KRAS/BRAF mutations are adverse independent prognostic factors in patients with synchronous primary and metastatic disease [203].
It has been shown that a limited resection margin is associated with an increased risk of recurrence [204], and recurrence after attempted curative resection is attributed to an involved resection margin [205]. However, neither the extent of the resection margin nor the type of hepatectomy (anatomic or non-anatomic) is a significant prognostic factor for OS and DFS or local recurrence [200]. In addition, intraoperative increased blood loss, increased transfusion requirements and increased number of fresh frozen plasma transfusion, adversely affect immediate postoperative morbidity and mortality, as well as long-term oncological outcomes [201,206]. Furthermore, increased immediate postoperative morbidity seems to be associated with impaired OS [49,207]. Additional prognostic factors of impaired oncological outcomes are: 1) an increased systemic 


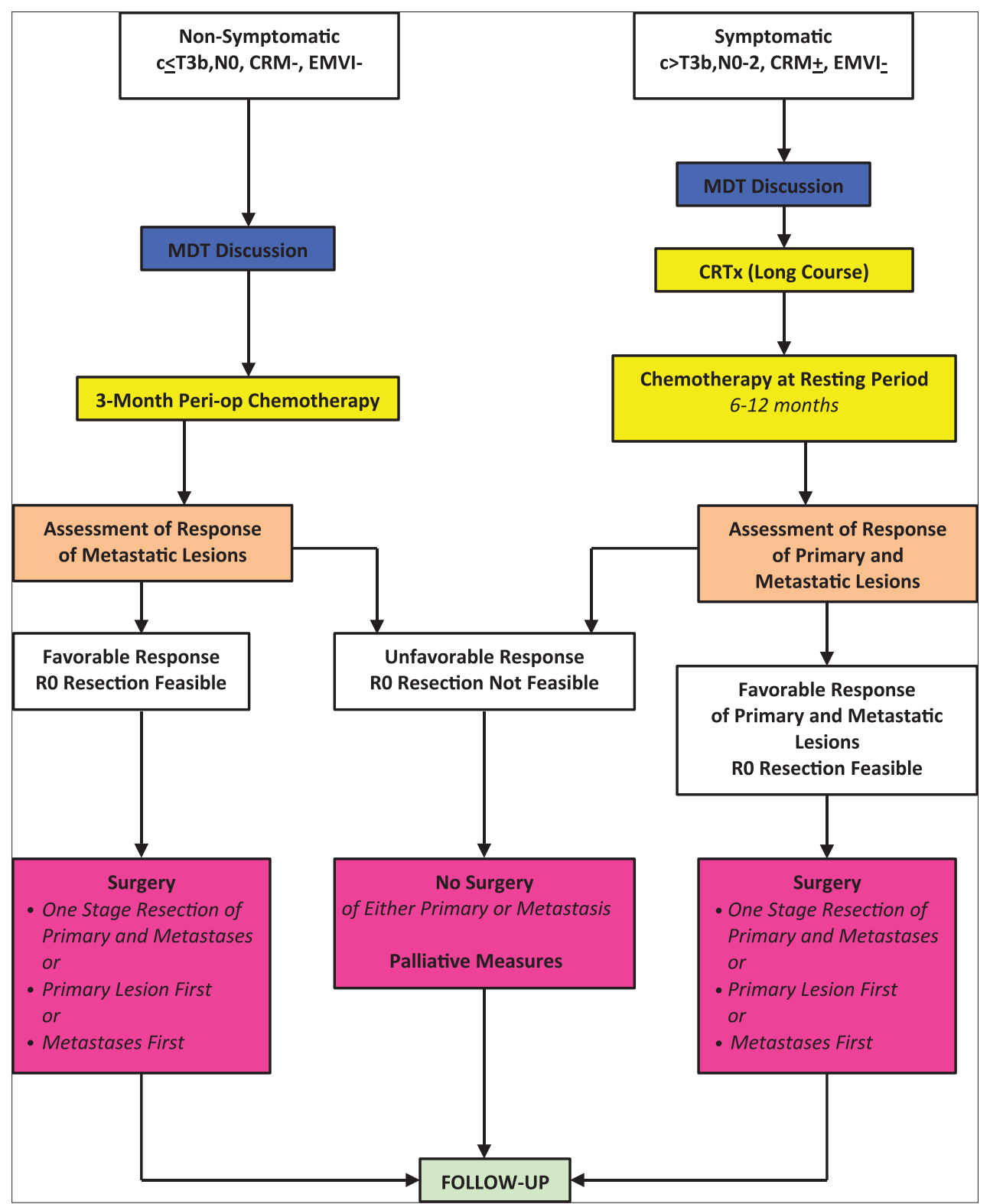

Figure 4 Strategy and treatment algorithm of synchronous rectal cancer and liver \pm lung metastases

CRM, circumferential resection margin; EMVI, extra-mural venous invasion; MDT, multi-disciplinary team; CRTx, chemo-radiotherapy

inflammatory response [206]; 2) neutrophils/lymphocytes ratio $>5$ [208]; 3) a less than twice increase in monocytes count [197] and increased serum VEGF and TIMP-1 concentrations.

Patients after curative resection of hepatic metastases should be followed-up regularly for local recurrence (liver US, CT, MRI) and metachronous extra-hepatic lesions (CT, PET-CT). The rate of metachronous extra-hepatic metastases is $19 \%$ [209]. In case of recurrent liver metastases, repeat curative resection is associated with acceptable morbidity and low mortality rates. 5-year survival rate after repeat liver resection could be more than $45 \%$, provided that a $\mathrm{R} 0$ resection has been achieved and there is no extra-hepatic
Table 3 Completeness of cytoreduction (CC) scoring

Residual peritoneal disease

CC scoring

\begin{tabular}{ll} 
No obvious disease & $\mathrm{CC}=0$ \\
Residual lesion $>0.25 \mathrm{~cm}$ & $\mathrm{CC}=1$ \\
Residual lesion $>0.25-<2.5 \mathrm{~cm}$ & $\mathrm{CC}=2$ \\
Residual lesion $>2.5 \mathrm{~cm}$ & $\mathrm{CC}=3$ \\
\hline
\end{tabular}

disease [210,211]. Liver transplantation is rarely indicated (treatment related morbidity), and only in case of absent extrahepatic disease [212]. 


\section{RECOMMENDATION}

Initially resectable synchronous disease

79. Preoperative chemotherapy helps select candidates for resections according to response. In most cases metastatic burden decreases or remains stable, and this response predicts better survival, reduced recurrence rate, and less non-therapeutic operations (LOE I, SOR A) (ROVC: 98\%)

80. Initially resectable synchronous disease, should be treated preoperatively with FOLFOX or FOLFIRI for 3 months, followed by resection of the primary tumor and metastases, either staged or synchronous, and postoperatively by chemotherapy with FOLFOX or FOLFIRI for 3-months (LOE II; SOR B) (ROVC: 85\%)

81. Preoperative chemotherapy should be limited (4-6 cycles), to reduce risk of potential hepatotoxicity (LOE II, SOR A) (ROVC 100\%)

82. Preoperative chemotherapy, leaving primary tumor intact, is considered safe, unless complications are pending (LOE II, SOR A) (ROVC: 97\%)

83. Prior to preoperative chemotherapy, marking of both primary lesion with Indian ink and hepatic metastases with metallic coils is recommended, as their location might be impossible after chemotherapy (LOE III, SOR D) (ROVC: 83\%)

84. Bevacizumab, in preoperative chemotherapeutic regimes, increases the risk of bleeding and perforation, and should be avoided in ulcerated lesions (LOE I, SOR A) (ROVC: 88\%)

85. Following induction chemotherapy, sequencing of procedures (simultaneous, or colorectal first, or liver fi rst) should be personalized and based on MDT discussion. Priority should be given to the more pressing disease component (LOE III, SOR B) (ROVC: 99\%)

86. Simultaneous resection of primary lesion and metastatic disease is recommended: 1) in case of a standard (not extended) colon resection with up to two segment hepatectomy; and 2) in case of extended colon or rectum resection with limited liver resection (LOE II, SOR B) (ROVC: 96\%)

87. In case of symptomatic primary and resectable systemic disease, resection of the primary tumor, and metastases if possible, should be performed upfront, followed by "adjuvant" chemotherapy for 6 months (LOE IV; SOR C) (ROVC: 92\%)

88. When a simultaneous resection is planned, liver resection is attempted first followed by colon or rectal resection (LOE II, SOR B) (ROVC: $82 \%$ )

89. Staged resection is suggested when major resections, both hepatic and colorectal, are anticipated (LOE II, SOR B) (ROVC: $100 \%$ )

90. Colon surgery is undertaken first in case of imminent complications (bleeding, obstruction, perforation). Following systemic chemotherapy,

\section{RECOMMENDATION}

resection of metastatic disease is attempted (LOE II, SOR B) (ROVC: 98\%)

91. In case of synchronous colon cancer and metastatic disease, resection of metastases is attempted first, when there is a risk of progression to an unresectable status if the patient remains off chemotherapy (LOE II, SOR B) (ROVC: 99\%)

92. In case of synchronous rectal cancer and resectable metastatic disease of substantial burden, the following sequence is proposed: 1) systemic chemotherapy; 2) metastases resection; 3) chemotherapy or chemoradiation for the rectal tumor according to indication (personalization); 4) rectal tumor resection; and 5) systemic chemotherapy (LOE II, SOR B) (ROVC: $89 \%$ )

93. Simultaneous resection seems to be associated with similar mortality, less morbidity and shorter length of stay, compared to staged resection (LOE II, SOR $\mathrm{B})$, although there is evidence that simultaneous resection could be associated with higher mortality (LOE II, SOR C) (ROVC: 97\%)

\section{RECOMMENDATIONS}

Initially unresectable metastatic disease, becoming potentially resectable aft er chemotherapy

94. In case of initial unresectable and secondary resectable metastatic disease aft er induction chemotherapy, resection of the primary tumor and metastases, either staged or synchronous, should be performed (LOE IV; SOR D) (ROVC: 99\%)

95. Higher rates of conversion of initially unresectable to resectable liver metastases are achieved, if systemic chemotherapy is combined with HIA, in highly specialized centers (LOE III, SOR C) (ROVC: 95\%)

96. Following resection of eventually resectable metastases of rectal cancer, the primary rectal lesion should be treated according to local stage of the disease (resection of rectum or radiotherapy followed by resection of rectum) (LOE IV; SOR D) (ROVC: 99\%)

97. In case of insuffi cient response of liver metastases to induction chemotherapy, surgical resection may not be performed, as primary tumor R0 resection does not improve survival (LOE III; SOR C) (ROVC: 87\%)

\section{RECOMMENDATIONS}

Definitely unresectable metastatic disease

98. Systemic chemotherapy is recommended to prevent further progression of the metastatic disease and related symptoms (LOE IV; SOR D) (ROVC: 95\%) 


\section{RECOMMENDATIONS}

Definitely unresectable metastatic disease

99. If first-line treatment fails to control progression of metastatic disease, loco-regional treatment, in the form of HIA chemotherapy, chemoradiation, chemoembolization, or ablative modalities, can be used, in highly specialized centers (LOE IV; SOR D) (ROVC: 94\%)

100. In case of a symptomatic primary lesion and synchronous unresectable systemic disease, resection of or other intervention (brachytherapy, stenting, etc) to the primary lesion should be performed, followed by systemic chemotherapy and further treatment according to response (LOE IV; SOR D) (ROVC: 96\%)

101. In case of unresectable systemic disease, there is no benefit from upfront surgery for a nonsymptomatic primary tumor. Instead, upfront systemic chemotherapy is recommended (LOE IV; SOR D) (ROVC: 97\%)

\section{Synchronous liver and lung metastatic disease}

After upfront systemic chemotherapy, R0 resection of both liver and lung metastases is associated with a reasonably high OS rate of more than 50\% [213]. Survival also depends on the number of extra-hepatic metastatic deposits [72].

\section{Management of peritoneal disease}

\section{Background}

The incidence of peritoneal carcinomatosis in CRC is around $11 \%$ [214], and until recently, peritoneal carcinomatosis has been considered as a terminal stage of the disease, liable to palliative treatment only. Systemic chemotherapy monotherapy (5-FU) in peritoneal disease is associated with a median survival of 5.2-12.6 months [214-216].

Maximal cytoreductive surgery using standard peritonectomy procedures, combined with perioperative intraperitoneal chemotherapy, either as hyperthermic intraoperative (HIPEC) or as early postoperative under normothermia (EPIC), has demonstrated a significant improvement in survival rates, in selected patients. Median survival of around 19 months and 3- and 5-year OS of 39\% and $19 \%$ respectively have been reported by several studies, most of them of low quality [216-228], and one metaanalysis [229].

Cytoreductive surgery with EPIC or HEPIC does not offer benefit to all patients with peritoneal carcinomatosis of colorectal origin, and proper patient selection is required. Extent of peritoneal involvement, as calculated by the Peritoneal Cancer Index (PCI) (Fig. 5) [216,217,219,221,223-226,230], and completeness of cytoreduction (CC), assessed by a specific CC-score, are the most important variables to determine oncological outcomes (Table 3). Bad prognostic factors are a $\mathrm{PCI}>13$, the presence of peritoneal nodules $>5 \mathrm{~cm}$ at the ligament of Treitz or adjacent to the root of jejunal mesentery and multiple segmental small bowel obstructions. Only, a R0 cytoreduction is of oncological benefit. Additional factors determining overall outcomes are good general PS, normal hematological profile, normal renal and liver function, absence of distant unresectable metastatic disease (liver, bone marrow, lung, brain), and absence of a second malignancy at risk for recurrence [216,217,219,221-227,231].

\section{Cytoreductive surgery}

Currently, peritonectomies include: 1) epigastric peritonectomy; 2) right and left subdiaphragmatic peritonectomy; 3) greater omentectomy and splenectomy; 4) lesser omentectomy; 5) cholecystectomy with resection of the omental bursa; 6) right and left lateral peritonectomy; 7) pelvic peritonectomy; and 8) resection of other organs if required to achieve a $\mathrm{R} 0$ resection.

\section{Perioperative intraperitoneal chemotherapy}

Even if the macroscopically visible tumor has been completely removed after maximal cytoreductive surgery, microscopic residual tumor at the peritoneal surfaces may be present, and secondary peritoneal tumors may appear within 2-3 years after initial surgery. The rationale of intraperitoneal chemotherapy is based on the fact that cytostatic agents exhibit a penetration of approximately 1-2 mm into tissues, and thus may result to the eradication of the microscopic residual tumor.

HIPEC enhances cytotoxicity and improves drug penetration. Heat itself has potential antitumor properties. HIPEC may be performed by an open or a closed technique with the use of specific devices. The most frequently cytotoxic drugs in use are mitomycin-C, cisplatin, doxorubicin, and oxaliplatin. Renal toxicity of intraperitoneal chemotherapy is avoided by careful monitoring of urine output during perfusion. EPIC under normothermia is used with the same intent as HIPEC, within the first five postoperative days after cytoreduction before intra-abdominal adhesion formation. Distribution and effectiveness of cytostatic drugs to penetrate the peritoneal-plasma barrier are inferior to that of HIPEC.

Hospital mortality after cytoreductive surgery and HIPEC or EPIC is $0-4 \%$. Hospital morbidity is high, ranging from $20 \%$ to $54 \%$, implying that the method must be performed at highly specialized centers $[218,220,221,232,233]$. According to 


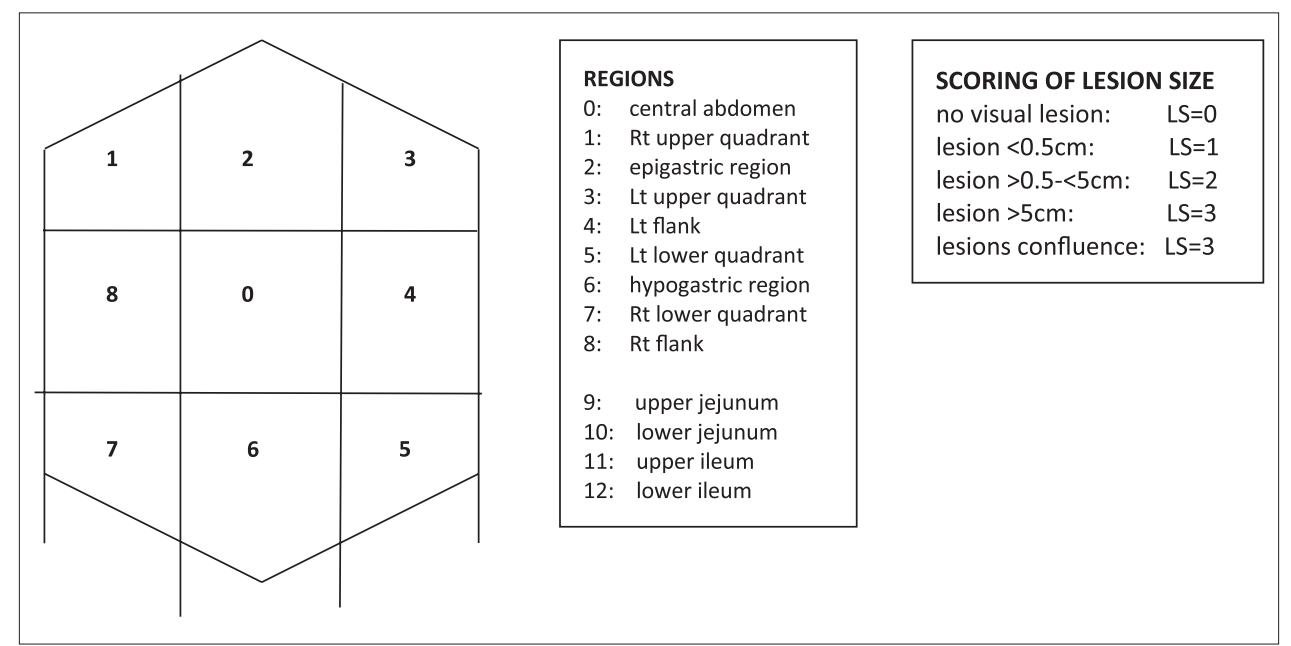

Figure 5 Assessment of peritoneal carcinomatosis with the use of the Peritoneal Cancer Index $R t$, right; $L t$, left; LS, lesion size

current literature, the 3-year survival rate ranges between $23 \%$ and $47 \%$. Patients in whom complete cytoreductive surgery was possible, had a median survival far superior than that in patients with incomplete cytoreductive surgery. Systematic chemotherapy should always be given after cytoreduction and intraperitoneal chemotherapy to improve oncological outcomes [217,221,227,234-236].

It appears that cytoreductive surgery with HIPEC or IPEC has a survival benefit over palliation with systemic chemotherapy alone. However, cytoreduction combined with HIPEC or IPEC does not seem to over any additional benefit over cytoreduction with systemic chemotherapy. Patients with resectable liver metastases should not be excluded from cytoreduction and HIPEC or IPEC [229,237].

\section{RECOMMENDATIONS}

102. In patients with peritoneal carcinomatosis of colorectal origin, the option of being treated with maximal cytoreductive surgery, combined with perioperative intraperitoneal chemotherapy, and followed by systemic chemotherapy, can be considered (LOE II; SOR B) (ROA: 97\%)

103. The procedures should be performed in specific centers (LOE II; SOR B) (ROA: 99\%)

104. Best oncological outcomes are obtained when a R0 cytoreduction is achieved and a limited extension of intraperitoneal disease is present, in fit patients (LOE II; SOR B) (ROA: 100\%)

\section{Bone metastases}

CRC metastases only to bones are extremely rare, and are usually associated with lung metastases. Resistant lung metastases predict potential disease progression to the bones, more than liver metastases. Treatment is palliative and consists of systemic chemotherapy and localized treatment (radiation, cyber-knife) to treat symptoms [238].

\section{Follow up after curative resection of primary disease}

Patient follow up depends on stage of the disease, quality of surgery, and amenability for intervention with either resection of recurrent disease or consideration of further systemic therapy. Four recent meta-analyses have shown that intensive follow up improves OS by $7-13 \%$ and is now considered as standard [239]. Generally, valid assessments are 3-monthly clinical visits for the first three years, followed by 6-monthly visits for further two years with clinical examination, evaluation of long-term toxicities (polyneuropathy after oxaliplatin), and CEA testing [240].

Complete colonoscopy must be performed at initial diagnosis, after three and afterwards every five years. If the diagnostic colonoscopy was incomplete, this should be repeated at 6 months after surgery. If follow-up colonoscopy shows advanced adenoma, successfully and completely excised, it should be repeated in one year.

In patients with high-risk disease, CT scan of the chest and abdomen every 6-12 months could be considered, although such close follow up should be confined to patients possibly amenable to resection of hepatic or pulmonary recurrence. Follow up CT scans should be performed with the same imaging protocols and contrast phases of enhancement. If MRI was used for the initial staging, MRI should also be used for the follow up, because CT images cannot be compared to MRI images due to different sensitivity/specificity [241]. Liver contrast-enhanced US could substitute for abdominal CT scan regarding follow up of liver metastases, particularly in young patients with no evidence of extra-hepatic disease [239,242]. Finally, routine PET-CT scanning is not recommended for surveillance [243]. 


\section{RECOMMENDATIONS}

105. Intensive follow up after curative resection of CRC metastases improves OS, and is strongly recommended (LOE I, SOR A) (ROVC: 96\%)

106. Follow up of colon and rectum is recommended as in non-metastatic disease, with clinical examination, serum CEA measurements and complete colonoscopy (LOE II, SOR A) (ROVC: 95\%)

107. Follow-up CT scans or/and MRI are performed in patients with potentially curable new recurrences. Same imaging protocols are performed as at the initial staging of the metastatic disease (LOE III SOR B) (ROVC: $97 \%$ )

108. Routine PET-CT scanning is not recommended (LOE III, SOR A) (ROVC: 98\%)

\section{Authors' affiliations}

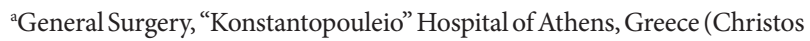
Dervenis); 'General Surgery, "InterClinic" Hospital of Heraklion, Greece (Evangelos Xynos); 'General Surgery, "Laikon" Hospital of Athens, Greece (George Sotiropoulos); 'General Surgery, "METROPOLITAN" Hospital of Piraeus, Greece (Nikolaos Gouvas); 'Medical Oncology, "Bioclinic" of Thessaloniki, Greece (Ioannis Boukovinas); ${ }^{\mathrm{f}}$ General Surgery, Athens Naval \& Veterans Hospital, Greece (Christos Agalianos, Ioannis Kyriazanos, George Pechlivanides); "Medical Oncology, "Venizeleion" Hospital of Heraklion, Greece (Nikolaos Androulakis); ${ }^{\mathrm{h}}$ Medical Oncology, "Koutlibaneion" Hospital of Larissa, Greece (Athanasios Athanasiadis); "Medical Oncology, "METROPOLITAN" Hospital of Piraeus, Greece (Christos Christodoulou); 'Radiology, University Hospital of Heraklion, Greece (Evangelia Chrysou); ${ }^{k}$ Medical Oncology, "Interbalkan" Medical Center, Thessaloniki, Greece (Christos Emmanoulidis); 'Colorectal Surgery, Chelsea and Westminster NHS Foundation Trust, London, UK (Panagiotis Georgiou, Paris Tekkis); ${ }^{\mathrm{m} M e d i c a l}$ Oncology, Dexeus University Institut, Barcelona, Spain (Niki Carachaliou); "Medical Oncology, "Iaso" General Hospital, Athens, Greece (Ourania Katopoidi); ${ }^{\circ}$ Medical Oncology, Oncology Center of Bank of Cyprus, Nicosia, Cyprus (Pandelis Kountourakis, Demetris

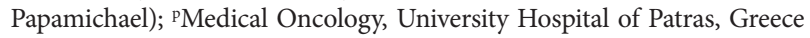
(Thomas Makatsoris); "Medical Oncology, "Ippokrateion" Hospital of Athens, Greece(PavlosPapakostas); ${ }^{\mathrm{r}}$ Medical Oncology, UniversityHospital of Ioannina, Greece (Georgios Pentheroudakis); 'Gastroenterology, "Theageneion" Cancer Hospital, Thessaloniki, Greece (Ioannis Pilpilidis); 'Medical Oncology, "Agioi Anargyroi" Hospital of Athens, Greece (Joseph Sgouros); "Radiology, "Konstantopouleio" Hospital of Athens, Greece (Charina Triantopoulou); "Pathology, University Hospital of Heraklion, Greece (Maria Tzardi); "Radiation Oncology, Oncology Center of Bank of Cyprus, Nicosia, Cyprus (Vassilis Vassiliou); ${ }^{x}$ Radiation Oncology, "Iatriko" Center of Athens, Greece (Lousa Vini); ${ }^{{ }^{M}}$ Medical Oncology, "George Gennimatas" General Hospital, Athens, Greece (Spyridon Xynogalos); ${ }^{2}$ Medical Oncology, "Metaxas" Cancer Hospital, Piraeus, Greece (Nikolaos Ziras); ${ }^{\circledR}$ Medical Oncology, University Hospital of Heraklion, Greece (John Souglakos)

\section{References}

1. Chuang SC, Su YC, Lu CY, et al. Risk factors for the development of metachronous liver metastasis in colorectal cancer patients after curative resection. World J Surg 2011;35:424-429.

2. Mori D, Shibaki M, Masuda M, Yamasaki F. Quantitative measurement of venous invasion of colorectal cancer with metachronous liver metastasis. Histopathology 2009;55:654-659.

3. Wang L, Wang L, Yu W, et al. Association between age and synchronous liver metastasis in female colorectal cancer patients. J Cancer Res Clin Oncol 2011;137:959-964.

4. Yoshida D, Ikeda Y, Waki K, et al. Different incidence of synchronous liver metastasis between proximal and distal colon cancer. Surg Today 2012;42:426-430.

5. Fujita S, Taniguchi H, Yao T, et al. Multi-institutional study of risk factors of liver metastasis from colorectal cancer: correlation with CD10 expression. Int J Colorectal Dis 2010;25:681-686.

6. Shen Z, Ye Y, Bin L, et al. Metabolic syndrome is an important factor for the evolution of prognosis of colorectal cancer: survival, recurrence, and liver metastasis. Am J Surg 2010;200:59-63.

7. Wu XZ, Ma F, Wang XL. Serological diagnostic factors for liver metastasis in patients with colorectal cancer. World J Gastroenterol 2010;16:4084-4088.

8. Qiu HB, Zhang LY, Zeng ZL, et al. HBV infection decreases risk of liver metastasis in patients with colorectal cancer: A cohort study. World J Gastroenterol 2011;17:804-808.

9. Yu DS, Li Y, Huang XE, et al. Effect of portal vein chemotherapy on liver metastasis after surgical resection of colorectal cancer. Asian Pac J Cancer Prev 2012;13:4699-4701.

10. Xynos E, Gouvas N, Triantopoulou C, et al. Clinical practice guidelines for the surgical management of colon cancer: a consensus statement of the Hellenic and Cypriot Colorectal Cancer Study Group by the HeSMO. Ann Gastroenterol 2016;29:3-17.

11. Nordlinger B, Van Cutsem E, Rougier P, et al. Does chemotherapy prior to liver resection increase the potential for cure in patients with metastatic colorectal cancer? A report from the European Colorectal Metastases Treatment Group. Eur J Cancer 2007;43:2037-2045.

12. House $M G$, Ito $H$, Gonen $M$, et al. Survival after hepatic resection for metastatic colorectal cancer: trends in outcomes for 1,600 patients during two decades at a single institution. J Am Coll Surg 2010;210:744-752, 752-755.

13. Lupinacci R, Penna C, Nordlinger B. Hepatectomy for resectable colorectal cancer metastases--indicators of prognosis, definition of resectability, techniques and outcomes. Surg Oncol Clin N Am 2007;16:493-506, vii-viii.

14. Nathan H, Bridges JF, Cosgrove DP, et al. Treating patients with colon cancer liver metastasis: a nationwide analysis of therapeutic decision making. Ann Surg Oncol 2012;19:3668-3676.

15. Muhi A, Ichikawa T, Motosugi U, et al. Diagnosis of colorectal hepatic metastases: comparison of contrast-enhanced CT, contrast-enhanced US, superparamagnetic iron oxide-enhanced MRI, and gadoxetic acid-enhanced MRI. J Magn Reson Imaging 2011;34:326-335.

16. Niekel MC, Bipat S, Stoker J. Diagnostic imaging of colorectal liver metastases with CT, MR imaging, FDG PET, and/or FDG PET/CT: a meta-analysis of prospective studies including patients who have not previously undergone treatment. Radiology 2010;257:674-684.

17. Tajima $\mathrm{T}$, Akahane $\mathrm{M}$, Takao $\mathrm{H}$, et al. Detection of liver metastasis: is diffusion-weighted imaging needed in Gd-EOBDTPA-enhanced MR imaging for evaluation of colorectal liver metastases? Jpn J Radiol 2012;30:648-658.

18. Samee A, Selvasekar CR. Current trends in staging rectal cancer. World J Gastroenterol 2011;17:828-834.

19. Cho YB, Chun HK, Kim MJ, et al. Accuracy of MRI and 18F-FDG PET/CT for restaging after preoperative concurrent chemoradiotherapy for rectal cancer. World J Surg 2009;33:26882694. 
20. Maas M, Rutten IJ, Nelemans PJ, et al. What is the most accurate whole-body imaging modality for assessment of local and distant recurrent disease in colorectal cancer? A meta-analysis: imaging for recurrent colorectal cancer. Eur J Nucl Med Mol Imaging 2011;38:1560-1571.

21. Park JM, Kim IY, Kim SW, et al. A comparative study of FDG PET/CT and enhanced multi-detector CT for detecting liver metastasis according to the size and location. Ann Nucl Med 2013;27:217-224.

22. Hariharan D, Constantinides V, Kocher HM, Tekkis PP. The role of laparoscopy and laparoscopic ultrasound in the preoperative staging of patients with resectable colorectal liver metastases: a meta-analysis. Am J Surg 2012;204:84-92.

23. Rau C, Blanc B, Ronot M, et al. Neither preoperative computed tomography nor intra-operative examination can predict metastatic lymph node in the hepatic pedicle in patients with colorectal liver metastasis. Ann Surg Oncol 2012;19:163-168.

24. Abdalla EK, Adam R, Bilchik AJ, et al. Improving resectability of hepatic colorectal metastases: expert consensus statement. Ann Surg Oncol 2006;13:1271-1280.

25. Choti MA, Sitzmann JV, Tiburi MF, et al. Trends in long-term survival following liver resection for hepatic colorectal metastases. Ann Surg 2002;235:759-766.

26. Tomlinson JS, Jarnagin WR, DeMatteo RP, et al. Actual 10-year survival after resection of colorectal liver metastases defines cure. J Clin Oncol 2007;25:4575-4580.

27. Gayowski TJ, Iwatsuki S, Madariaga JR, et al. Experience in hepatic resection for metastatic colorectal cancer: analysis of clinical and pathologic risk factors. Surgery 1994;116:703-710; discussion 710-711.

28. Scheele J, Stang R, Altendorf-Hofmann A, Paul M. Resection of colorectal liver metastases. World J Surg 1995;19:59-71.

29. Abdalla EK, Bauer TW, Chun YS, et al. Locoregional surgical and interventional therapies for advanced colorectal cancer liver metastases: expert consensus statements. HPB (Oxford) 2013;15:119-130.

30. Charnsangavej C, Clary B, Fong Y, et al. Selection of patients for resection of hepatic colorectal metastases: expert consensus statement. Ann Surg Oncol 2006;13:1261-1268.

31. Minagawa M, Makuuchi M, Torzilli G, et al. Extension of the frontiers of surgical indications in the treatment of liver metastases from colorectal cancer: long-term results. Ann Surg 2000;231:487-499.

32. Urdzik J, Bjerner $\mathrm{T}$, Wanders $\mathrm{A}$, et al. The value of preoperative magnetic resonance spectroscopy in the assessment of steatohepatitis in patients with colorectal liver metastasis. J Hepatol 2012;56:640-646.

33. Nordlinger B, Sorbye H, Glimelius B, et al. Perioperative chemotherapy with FOLFOX4 and surgery versus surgery alone for resectable liver metastases from colorectal cancer (EORTC Intergroup trial 40983): a randomised controlled trial. Lancet 2008;371:1007-1016.

34. Hasegawa K, Takahashi $M$, Ohba $M$, et al. Perioperative chemotherapy and liver resection for hepatic metastases of colorectal cancer. J Hepatobiliary Pancreat Sci 2012;19:503-508.

35. Pawlik TM, Cosgrove D. The role of peri-operative chemotherapy for resectable colorectal liver metastasis: what does the evidence support? J Gastrointest Surg 2011;15:410-415.

36. Schulz A, Dormagen JB, Drolsum A, et al. Impact of contrastenhanced intraoperative ultrasound on operation strategy in case of colorectal liver metastasis. Acta Radiol 2012;53:1081-1087.

37. Viana EF, Herman P, Coelho FF, et al. The role of hilar lymphadenectomy in patients subjected to hepatectomy due to colorectal metastasis. Arq Gastroenterol 2011;48:217-219.

38. Ishibashi $\mathrm{K}$, Ishida $\mathrm{H}$, Ohsawa $\mathrm{T}$, et al. Impact of hepatic lymph node metastasis on survival of patients with synchronous resectable or unresectable liver metastases of colorectal cancer. Tech Coloproctol 2013;17:51-57.

39. Gold JS, Are C, Kornprat P, et al. Increased use of parenchymalsparing surgery for bilateral liver metastases from colorectal cancer is associated with improved mortality without change in oncologic outcome: trends in treatment over time in 440 patients. Ann Surg 2008;247:109-117.

40. Torzilli G, Procopio F, Botea F, et al. One-stage ultrasonographically guided hepatectomy for multiple bilobar colorectal metastases: a feasible and effective alternative to the 2-stage approach. Surgery 2009;146:60-71.

41. Adam R, Miller R, Pitombo M, et al. Two-stage hepatectomy approach for initially unresectable colorectal hepatic metastases. Surg Oncol Clin N Am 2007;16:525-536, viii.

42. Brouquet A, Abdalla EK, Kopetz S, et al. High survival rate after two-stage resection of advanced colorectal liver metastases: response-based selection and complete resection define outcome. J Clin Oncol 2011;29:1083-1090.

43. D’Amico FE, Allen PJ, Eaton AA, et al. Vascular inflow control during hemi-hepatectomy: a comparison between intrahepatic pedicle ligation and extrahepatic vascular ligation. $H P B$ (Oxford) 2013;15:449-456.

44. Turrini O, Ewald J, Viret F, et al. Two-stage hepatectomy: who will not jump over the second hurdle? Eur J Surg Oncol 2012;38:266-273.

45. Goere D, Farges O, Leporrier J, et al. Chemotherapy does not impair hypertrophy of the left liver after right portal vein obstruction. J Gastrointest Surg 2006;10:365-370.

46. Zorzi D, Chun YS, Madoff DC, Abdalla EK, Vauthey JN. Chemotherapy with bevacizumab does not affect liver regeneration after portal vein embolization in the treatment of colorectal liver metastases. Ann Surg Oncol 2008;15:2765-2772.

47. Mentha G, Terraz S, Morel P, et al. Dangerous halo after neoadjuvant chemotherapy and two-step hepatectomy for colorectal liver metastases. Br J Surg 2009;96:95-103.

48. Kokudo N, Imamura H, Sugawara Y, et al. Surgery for multiple hepatic colorectal metastases. J Hepatobiliary Pancreat Surg 2004;11:84-91.

49. Matsuda A, Miyashita M, Matsumoto S, et al. Hepatic pedicle clamping does not worsen survival after hepatic resection for colorectal liver metastasis: results from a systematic review and meta-analysis. Ann Surg Oncol 2013;20:3771-3778.

50. Weiss MJ, Ito H, Araujo RL, et al. Hepatic pedicle clamping during hepatic resection for colorectal liver metastases: no impact on survival or hepatic recurrence. Ann Surg Oncol 2013;20:285-294.

51. Guerron AD, Aliyev S, Agcaoglu O, et al. Laparoscopic versus open resection of colorectal liver metastasis. Surg Endosc 2013;27:1138-1143.

52. Ho CM, Wakabayashi G, Nitta H, et al. Systematic review of robotic liver resection. Surg Endosc 2013;27:732-739.

53. Mayo SC, Heckman JE, Shore AD, et al. Shifting trends in liverdirected management of patients with colorectal liver metastasis: a population-based analysis. Surgery 2011;150:204-216.

54. Abdalla EK, Vauthey JN, Ellis LM, et al. Recurrence and outcomes following hepatic resection, radiofrequency ablation, and combined resection/ablation for colorectal liver metastases. Ann Surg 2004;239:818-825; discussion 825-817.

55. de Jong MC, van Dam RM, Maas M, et al. The liver-first approach for synchronous colorectal liver metastasis: a 5-year single-centre experience. HPB (Oxford) 2011;13:745-752.

56. Mulier S, Ni Y, Jamart J, et al. Local recurrence after hepatic radiofrequency coagulation: multivariate meta-analysis and review of contributing factors. Ann Surg 2005;242:158-171.

57. Tanaka K, Shimada H, Nagano Y, et al. Outcome after hepatic resection versus combined resection and microwave ablation for multiple bilobar colorectal metastases to the liver. Surgery 
2006;139:263-273.

58. Wu YZ, Li B, Wang T, Wang SJ, Zhou YM. Radiofrequency ablation vs hepatic resection for solitary colorectal liver metastasis: a metaanalysis. World J Gastroenterol 2011;17:4143-4148.

59. Kim KH, Yoon YS, Yu CS, et al. Comparative analysis of radiofrequency ablation and surgical resection for colorectal liver metastases. J Korean Surg Soc 2011;81:25-34.

60. Lee $\mathrm{KH}, \mathrm{Kim} \mathrm{HO}$, Yoo $\mathrm{CH}$, et al. Comparison of radiofrequency ablation and resection for hepatic metastasis from colorectal cancer. Korean J Gastroenterol 2012;59:218-223.

61. Schiffman SC, Bower M, Brown RE, et al. Hepatectomy is superior to thermal ablation for patients with a solitary colorectal liver metastasis. J Gastrointest Surg 2010;14:1881-1886; discussion 1886-1887.

62. Kemeny MM, Adak S, Gray B, et al. Combined-modality treatment for resectable metastatic colorectal carcinoma to the liver: surgical resection of hepatic metastases in combination with continuous infusion of chemotherapy--an intergroup study. J Clin Oncol 2002;20:1499-1505.

63. Portier G, Elias D, Bouche O, et al. Multicenter randomized trial of adjuvant fluorouracil and folinic acid compared with surgery alone after resection of colorectal liver metastases: FFCD ACHBTH AURC 9002 trial. J Clin Oncol 2006;24:4976-4982.

64. Kanemitsu Y, Kato T, Shimizu Y, et al. A randomized phase II/ III trial comparing hepatectomy followed by mFOLFOX6 with hepatectomy alone as treatment for liver metastasis from colorectal cancer: Japan Clinical Oncology Group Study JCOG0603. Jpn J Clin Oncol 2009;39:406-409.

65. Kemeny N, Huang Y, Cohen AM, et al. Hepatic arterial infusion of chemotherapy after resection of hepatic metastases from colorectal cancer. N Engl J Med 1999;341:2039-2048.

66. Kemeny NE, Gonen M. Hepatic arterial infusion after liver resection. N Engl J Med 2005;352:734-735.

67. Nelson R, Freels S. Hepatic artery adjuvant chemotherapy for patients having resection or ablation of colorectal cancer metastatic to the liver. Cochrane Database Syst Rev 2006CD003770.

68. Konopke R, Kersting S, Bunk A, et al. Colorectal liver metastasis surgery: analysis of risk factors predicting postoperative complications in relation to the extent of resection. Int J Colorectal Dis 2009;24:687-697.

69. Ribeiro HS, Costa WL, Jr., Diniz AL, et al. Extended preoperative chemotherapy, extent of liver resection and blood transfusion are predictive factors of liver failure following resection of colorectal liver metastasis. Eur J Surg Oncol 2013;39:380-385.

70. Wolf PS, Park JO, Bao F, et al. Preoperative chemotherapy and the risk of hepatotoxicity and morbidity after liver resection for metastatic colorectal cancer: a single institution experience. J Am Coll Surg 2013;216:41-49.

71. Nakajima J, Murakawa T, Fukami T, Takamoto S. Is thoracoscopic surgery justified to treat pulmonary metastasis from colorectal cancer? Interact Cardiovasc Thorac Surg 2008;7:212-216; discussion 216-217.

72. Pulitano C, Bodingbauer M, Aldrighetti L, et al. Liver resection for colorectal metastases in presence of extrahepatic disease: results from an international multi-institutional analysis. Ann Surg Oncol 2011;18:1380-1388.

73. Watanabe K, Nagai K, Kobayashi A, Sugito M, Saito N. Factors influencing survival after complete resection of pulmonary metastases from colorectal cancer. Br J Surg 2009;96:1058-1065.

74. Zabaleta J, Aguinagalde B, Fuentes MG, et al. Survival after lung metastasectomy for colorectal cancer: importance of previous liver metastasis as a prognostic factor. Eur J Surg Oncol 2011:37:786-790.

75. Amado RG, Wolf M, Peeters M, et al. Wild-type KRAS is required for panitumumab efficacy in patients with metastatic colorectal cancer. J Clin Oncol 2008;26:1626-1634.
76. Douillard JY, Oliner KS, Siena S, et al. Panitumumab-FOLFOX4 treatment and RAS mutations in colorectal cancer. $N$ Engl J Med 2013;369:1023-1034.

77. Karapetis CS, Khambata-Ford S, Jonker DJ, et al. K-ras mutations and benefit from cetuximab in advanced colorectal cancer. $N$ Engl J Med 2008;359:1757-1765.

78. Van Cutsem E, Kohne $\mathrm{CH}$, Lang I, et al. Cetuximab plus irinotecan, fluorouracil, and leucovorin as first-line treatment for metastatic colorectal cancer: updated analysis of overall survival according to tumor KRAS and BRAF mutation status. $J$ Clin Oncol 2011;29:2011-2019.

79. Adam R, Wicherts DA, de Haas RJ, et al. Patients with initially unresectable colorectal liver metastases: is there a possibility of cure? J Clin Oncol 2009;27:1829-1835.

80. Blazer DG, $3^{\text {rd }}$, Kishi Y, Maru DM, et al. Pathologic response to preoperative chemotherapy: a new outcome end point after resection of hepatic colorectal metastases. J Clin Oncol 2008;26:5344-5351.

81. Kataoka K, Kanazawa A, Nakajima A, et al. Feasibility and potential benefit of preoperative chemotherapy for colorectal liver metastasis (CLM): a single-centered retrospective study. Surg Today 2013;43:1154-1161.

82. Robinson S, Manas DM, Pedley I, Mann D, White SA. Systemic chemotherapy and its implications for resection of colorectal liver metastasis. Surg Oncol 2011;20:57-72.

83. Abad A, Massuti B, Anton A, et al. Colorectal cancer metastasis resectability after treatment with the combination of oxaliplatin, irinotecan and 5-fluorouracil. Final results of a phase II study. Acta Oncol 2008;47:286-292.

84. Andres A, Toso C, Adam R, et al. A survival analysis of the liverfirst reversed management of advanced simultaneous colorectal liver metastases: a LiverMetSurvey-based study. Ann Surg 2012;256:772-778; discussion 778-779.

85. Montagnani F, Chiriatti A, Licitra S, Aliberti C, Fiorentini G. Differences in efficacy and safety between capecitabine and infusional 5-fluorouracil when combined with irinotecan for the treatment of metastatic colorectal cancer. Clin Colorectal Cancer 2010;9:243-247.

86. Maughan TS, Adams RA, Smith CG, et al. Addition of cetuximab to oxaliplatin-based first-line combination chemotherapy for treatment of advanced colorectal cancer: results of the randomised phase 3 MRC COIN trial. Lancet 2011;377:2103-2114.

87. Bokemeyer C, Bondarenko I, Makhson A, et al. Fluorouracil, leucovorin, and oxaliplatin with and without cetuximab in the first-line treatment of metastatic colorectal cancer. J Clin Oncol 2009;27:663-671.

88. Van Cutsem E, Kohne $\mathrm{CH}$, Hitre E, et al. Cetuximab and chemotherapy as initial treatment for metastatic colorectal cancer. N Engl J Med 2009;360:1408-1417.

89. Saltz LB, Clarke S, Diaz-Rubio E, et al. Bevacizumab in combination with oxaliplatin-based chemotherapy as first-line therapy in metastatic colorectal cancer: a randomized phase III study. J Clin Oncol 2008;26:2013-2019.

90. Chaudhury P, Hassanain M, Bouganim N, et al. Perioperative chemotherapy with bevacizumab and liver resection for colorectal cancer liver metastasis. HPB (Oxford) 2010;12:37-42.

91. Falcone A, Ricci S, Brunetti I, et al. Phase III trial of infusional fluorouracil, leucovorin, oxaliplatin, and irinotecan (FOLFOXIRI) compared with infusional fluorouracil, leucovorin, and irinotecan (FOLFIRI) as first-line treatment for metastatic colorectal cancer: the Gruppo Oncologico Nord Ovest. J Clin Oncol 2007;25:16701676.

92. Souglakos J, Androulakis N, Syrigos K, et al. FOLFOXIRI (folinic acid, 5-fluorouracil, oxaliplatin and irinotecan) vs FOLFIRI (folinic acid, 5-fluorouracil and irinotecan) as first-line treatment in metastatic colorectal cancer (MCC): a multicentre randomised 
phase III trial from the Hellenic Oncology Research Group (HORG). Br J Cancer 2006;94:798-805.

93. Folprecht G, Gruenberger T, Bechstein W, et al. Survival of patients with initially unresectable colorectal liver metastases treated with FOLFOX/cetuximab or FOLFIRI/cetuximab in a multidisciplinary concept (CELIM study). Ann Oncol 2014;25:1018-1025.

94. Seymour MT, Maughan TS, Ledermann JA, et al. Different strategies of sequential and combination chemotherapy for patients with poor prognosis advanced colorectal cancer (MRC FOCUS): a randomised controlled trial. Lancet 2007;370:143-152.

95. Koopman M, Antonini NF, Douma J, et al. Sequential versus combination chemotherapy with capecitabine, irinotecan, and oxaliplatin in advanced colorectal cancer (CAIRO): a phase III randomised controlled trial. Lancet 2007;370:135-142.

96. Pawlik TM, Olino K, Gleisner AL, et al. Preoperative chemotherapy for colorectal liver metastases: impact on hepatic histology and postoperative outcome. J Gastrointest Surg 2007;11:860-868.

97. Vauthey JN, Pawlik TM, Ribero D, et al. Chemotherapy regimen predicts steatohepatitis and an increase in 90-day mortality after surgery for hepatic colorectal metastases. J Clin Oncol 2006;24:2065-2072.

98. Schmoll HJ, Van Cutsem E, Stein A, et al. ESMO Consensus Guidelines for management of patients with colon and rectal cancer. a personalized approach to clinical decision making. Ann Oncol 2012;23:2479-2516.

99. Folprecht G, Grothey A, Alberts S, Raab HR, Kohne CH. Neoadjuvant treatment of unresectable colorectal liver metastases: correlation between tumour response and resection rates. Ann Oncol 2005; 16:1311-1319.

100. Tournigand C, Cervantes A, Figer A, et al. OPTIMOX1: a randomized study of FOLFOX4 or FOLFOX7 with oxaliplatin in a stop-and-Go fashion in advanced colorectal cancer--a GERCOR study. J Clin Oncol 2006;24:394-400.

101. Chibaudel B, Maindrault-Goebel F, Lledo G, et al. Can chemotherapy be discontinued in unresectable metastatic colorectal cancer? The GERCOR OPTIMOX2 Study. J Clin Oncol 2009;27:5727-5733.

102. Goere D, Deshaies I, de Baere T, et al. Prolonged survival of initially unresectable hepatic colorectal cancer patients treated with hepatic arterial infusion of oxaliplatin followed by radical surgery of metastases. Ann Surg 2010;251:686-691.

103. Kemeny NE, Melendez FD, Capanu M, et al. Conversion to resectability using hepatic artery infusion plus systemic chemotherapy for the treatment of unresectable liver metastases from colorectal carcinoma. J Clin Oncol 2009;27:3465-3471.

104. Kemeny NE, Niedzwiecki D, Hollis DR, et al. Hepatic arterial infusion versus systemic therapy for hepatic metastases from colorectal cancer: a randomized trial of efficacy, quality of life, and molecular markers (CALGB 9481). J Clin Oncol 2006;24:1395-1403.

105. Kerr DJ, McArdle CS, Ledermann J, et al. Intrahepatic arterial versus intravenous fluorouracil and folinic acid for colorectal cancer liver metastases: a multicentre randomised trial. Lancet 2003;361:368-373.

106. Mocellin S, Pilati P, Lise M, Nitti D. Meta-analysis of hepatic arterial infusion for unresectable liver metastases from colorectal cancer: the end of an era? J Clin Oncol 2007;25:5649-5654.

107. Ensminger WD. Intrahepatic arterial infusion of chemotherapy: pharmacologic principles. Semin Oncol 2002;29:119-125.

108. Gluck WL, Akwari OE, Kelvin FM, Goodwin BJ. A reversible enteropathy complicating continuous hepatic artery infusion chemotherapy with 5-fluoro-2-deoxyuridine. Cancer 1985;56:2424-2427.

109. Kemeny MM, Battifora H, Blayney DW, et al. Sclerosing cholangitis after continuous hepatic artery infusion of FUDR.
Ann Surg 1985;202:176-181.

110. Kemeny N, Seiter K, Niedzwiecki D, et al. A randomized trial of intrahepatic infusion of fluorodeoxyuridine with dexamethasone versus fluorodeoxyuridine alone in the treatment of metastatic colorectal cancer. Cancer 1992;69:327-334.

111. Boige V, Malka D, Elias D, et al. Hepatic arterial infusion of oxaliplatin and intravenous LV5FU2 in unresectable liver metastases from colorectal cancer after systemic chemotherapy failure. Ann Surg Oncol 2008;15:219-226.

112. Ducreux M, Ychou M, Laplanche A, et al. Hepatic arterial oxaliplatin infusion plus intravenous chemotherapy in colorectal cancer with inoperable hepatic metastases: a trial of the gastrointestinal group of the Federation Nationale des Centres de Lutte Contre le Cancer. J Clin Oncol 2005;23:4881-4887.

113. Poggi G, Quaretti P, Minoia C, et al. Transhepatic arterial chemoembolization with oxaliplatin-eluting microspheres (OEM-TACE) for unresectable hepatic tumors. Anticancer Res 2008;28:3835-3842.

114. Stagg RJ, Venook AP, Chase JL, et al. Alternating hepatic intraarterial floxuridine and fluorouracil: a less toxic regimen for treatment of liver metastases from colorectal cancer. J Natl Cancer Inst 1991;83:423-428.

115. Takamoto T, Hashimoto T, Sano K, et al. Recovery of liver function after the cessation of preoperative chemotherapy for colorectal liver metastasis. Ann Surg Oncol 2010;17:2747-2755.

116. Gaujoux S, Goere D, Dumont F, et al. Complete radiological response of colorectal liver metastases after chemotherapy: what can we expect? Dig Surg 2011;28:114-120.

117. Ramia-Angel JM, la Plaza RD, Quinones JE. Complete clinical response of liver metastasis after chemotherapy: To resect or not? World J Gastrointest Oncol 2011;3:107-110.

118. Gwak JH, Oh BY, Lee RA, Chung SS, Kim KH. Clinical applications of radio-frequency ablation in liver metastasis of colorectal cancer. J Korean Soc Coloproctol 2011;27:202-210.

119. Hompes D, Prevoo W, Ruers T. Radiofrequency ablation as a treatment tool for liver metastases of colorectal origin. Cancer Imaging 2011;11:23-30.

120. Kingham TP, Tanoue M, Eaton A, et al. Patterns of recurrence after ablation of colorectal cancer liver metastases. Ann Surg Oncol 2012;19:834-841.

121. Mulier S, Mulier P, Ni Y, et al. Complications of radiofrequency coagulation of liver tumours. Br J Surg 2002;89:1206-1222.

122. Rocha FG, D’Angelica M. Treatment of liver colorectal metastases: role of laparoscopy, radiofrequency ablation, and microwave coagulation. J Surg Oncol 2010;102:968-974.

123. Stang A, Fischbach R, Teichmann W, Bokemeyer C, Braumann D. A systematic review on the clinical benefit and role of radiofrequency ablation as treatment of colorectal liver metastases. Eur J Cancer 2009;45:1748-1756.

124. Iannitti DA, Martin RC, Simon CJ, et al. Hepatic tumor ablation with clustered microwave antennae: the US Phase II trial. HPB (Oxford) 2007;9:120-124.

125. Martin RC, Scoggins CR, McMasters KM. Safety and efficacy of microwave ablation of hepatic tumors: a prospective review of a 5-year experience. Ann Surg Oncol 2010;17:171-178.

126. Capussotti L, Muratore A, Baracchi F, et al. Portal vein ligation as an efficient method of increasing the future liver remnant volume in the surgical treatment of colorectal metastases. Arch Surg 2008;143:978-982; discussion 982.

127. Abulkhir A, Limongelli P, Healey AJ, et al. Preoperative portal vein embolization for major liver resection: a meta-analysis. Ann Surg 2008;247:49-57.

128. Yamashita S, Hasegawa K, Takahashi M, et al. One-stage hepatectomy following portal vein embolization for colorectal liver metastasis. World J Surg 2013;37:622-628.

129. Schnitzbauer AA, Lang SA, Goessmann H, et al. Right portal vein 
ligation combined with in situ splitting induces rapid left lateral liver lobe hypertrophy enabling 2-staged extended right hepatic resection in small-for-size settings. Ann Surg 2012;255:405-414.

130. Tang JT, Wang JL, Fang JY. Meta-analysis: perioperative regional liver chemotherapy for improving survival and preventing liver metastases in patients with colorectal carcinoma. J Dig Dis 2010;11:208-214.

131. Aloia T, Sebagh M, Plasse M, et al. Liver histology and surgical outcomes after preoperative chemotherapy with fluorouracil plus oxaliplatin in colorectal cancer liver metastases. J Clin Oncol 2006;24:4983-4990.

132. Karoui M, Penna C, Amin-Hashem M, et al. Influence of preoperative chemotherapy on the risk of major hepatectomy for colorectal liver metastases. Ann Surg 2006;243:1-7.

133. Nakano H, Oussoultzoglou E, Rosso E, et al. Sinusoidal injury increases morbidity after major hepatectomy in patients with colorectal liver metastases receiving preoperative chemotherapy. Ann Surg 2008;247:118-124.

134. Gravante G, Overton J, Sorge R, et al. Radiofrequency ablation versus resection for liver tumours: an evidence-based approach to retrospective comparative studies. J Gastrointest Surg 2011;15:378-387.

135. Mulier S, Ni Y, Jamart J, et al. Radiofrequency ablation versus resection for resectable colorectal liver metastases: time for a randomized trial? Ann Surg Oncol 2008;15:144-157.

136. Van Tilborg AA, Meijerink MR, Sietses C, et al. Long-term results of radiofrequency ablation for unresectable colorectal liver metastases: a potentially curative intervention. $\mathrm{Br} J$ Radiol 2011;84:556-565.

137. Gillams AR, Lees WR. Five-year survival in 309 patients with colorectal liver metastases treated with radiofrequency ablation. Eur Radiol 2009;19:1206-1213.

138. Lencioni R, Crocetti L, Cioni D, Della Pina C, Bartolozzi C. Percutaneous radiofrequency ablation of hepatic colorectal metastases: technique, indications, results, and new promises. Invest Radiol 2004;39:689-697.

139. Gillams AR, Lees WR. Radio-frequency ablation of colorectal liver metastases in 167 patients. Eur Radiol 2004;14:2261-2267.

140. Hammill CW, Billingsley KG, Cassera MA, et al. Outcome after laparoscopic radiofrequency ablation of technically resectable colorectal liver metastases. Ann Surg Oncol 2011;18:1947-1954.

141. Chang DT, Swaminath A, Kozak M, et al. Stereotactic body radiotherapy for colorectal liver metastases: a pooled analysis. Cancer 2011;117:4060-4069.

142. Dawood O, Mahadevan A, Goodman KA. Stereotactic body radiation therapy for liver metastases. Eur J Cancer 2009;45:29472959.

143. Petersen JB, Lassen Y, Hansen AT, et al. Normal liver tissue sparing by intensity-modulated proton stereotactic body radiotherapy for solitary liver tumours. Acta Oncol 2011;50:823-828.

144. Rule W, Timmerman R, Tong L, et al. Phase I dose-escalation study of stereotactic body radiotherapy in patients with hepatic metastases. Ann Surg Oncol 2011;18:1081-1087.

145. van der Pool AE, Mendez Romero A, Wunderink W, et al. Stereotactic body radiation therapy for colorectal liver metastases. Br J Surg 2010;97:377-382.

146. Akhlaghpoor S, Aziz-Ahari A, Amoui M, et al. Short-term effectiveness of radiochemoembolization for selected hepatic metastases with a combination protocol. World J Gastroenterol 2012;18:5249-5259.

147. Popperl G, Helmberger T, Munzing W, et al. Selective internal radiation therapy with SIR-Spheres in patients with nonresectable liver tumors. Cancer Biother Radiopharm 2005;20:200-208.

148. Cosimelli M, Golfieri R, Cagol PP, et al. Multi-centre phase II clinical trial of yttrium-90 resin microspheres alone in unresectable, chemotherapy refractory colorectal liver metastases. Br J Cancer 2010;103:324-331.

149. Gray B, Van Hazel G, Hope M, et al. Randomised trial of SIRSpheres plus chemotherapy vs. chemotherapy alone for treating patients with liver metastases from primary large bowel cancer. Ann Oncol 2001;12:1711-1720.

150. Kennedy AS, Nutting C, Coldwell D, Gaiser J, Drachenberg C. Pathologic response and microdosimetry of (90)Y microspheres in man: review of four explanted whole livers. Int J Radiat Oncol Biol Phys 2004;60:1552-1563.

151. Lewandowski RJ, Thurston KG, Goin JE, et al. 90Y microsphere (TheraSphere) treatment for unresectable colorectal cancer metastases of the liver: response to treatment at targeted doses of 135-150 Gy as measured by [18F]fluorodeoxyglucose positron emission tomography and computed tomographic imaging. J Vasc Interv Radiol 2005;16:1641-1651.

152. Martin RC, Joshi J, Robbins K, et al. Transarterial chemoembolization of metastatic colorectal carcinoma with drug-eluting beads, irinotecan (DEBIRI): multi-institutional registry. J Oncol 2009;2009:539795.

153. Martin RC, Robbins K, Tomalty D, et al. Transarterial chemoembolisation (TACE) using irinotecan-loaded beads for the treatment of unresectable metastases to the liver in patients with colorectal cancer: an interim report. World J Surg Oncol 2009;7:80.

154. Vogl TJ, Zangos S, Eichler K, Yakoub D, Nabil M. Colorectal liver metastases: regional chemotherapy via transarterial chemoembolization (TACE) and hepatic chemoperfusion: an update. Eur Radiol 2007;17:1025-1034.

155. Beppu T, Sakamoto Y, Hasegawa K, et al. A nomogram predicting disease-free survival in patients with colorectal liver metastases treated with hepatic resection: multicenter data collection as a Project Study for Hepatic Surgery of the Japanese Society of Hepato-Biliary-Pancreatic Surgery. J Hepatobiliary Pancreat Sci 2012;19:72-84.

156. Fong Y, Fortner J, Sun RL, Brennan MF, Blumgart LH. Clinical score for predicting recurrence after hepatic resection for metastatic colorectal cancer: analysis of 1001 consecutive cases. Ann Surg 1999;230:309-318; discussion 318-321.

157. Nordlinger B, Guiguet M, Vaillant JC, et al. Surgical resection of colorectal carcinoma metastases to the liver. A prognostic scoring system to improve case selection, based on 1568 patients. Association Francaise de Chirurgie. Cancer 1996;77:1254-1262.

158. Schlag P, Hohenberger P, Herfarth C. Resection of liver metastases in colorectal cancer--competitive analysis of treatment results in synchronous versus metachronous metastases. Eur J Surg Oncol 1990;16:360-365.

159. Tsai MS, Su YH, Ho MC, et al. Clinicopathological features and prognosis in resectable synchronous and metachronous colorectal liver metastasis. Ann Surg Oncol 2007; 14:786-794.

160. Adam R, Bismuth H, Castaing D, et al. Repeat hepatectomy for colorectal liver metastases. Ann Surg 1997;225:51-60; discussion 60-52.

161. Bockhorn M, Frilling A, Fruhauf NR, et al. Survival of patients with synchronous and metachronous colorectal liver metastases-is there a difference? J Gastrointest Surg 2008;12:1399-1405.

162. Ng WW, Cheung YS, Wong J, Lee KF, Lai PB. A preliminary analysis of combined liver resection with new chemotherapy for synchronous and metachronous colorectal liver metastasis. Asian J Surg 2009;32:189-197.

163. Xu J, Wei Y, Zhong Y, et al. Hepatectomy for liver metastasis of colorectal cancer. Int J Colorectal Dis 2009;24:419-425.

164. Zhang S, Gao F, Luo J, Yang J. Prognostic factors in survival of colorectal cancer patients with synchronous liver metastasis. Colorectal Dis 2010;12:754-761.

165. Benoist S, Pautrat K, Mitry E, et al. Treatment strategy for 
patients with colorectal cancer and synchronous irresectable liver metastases. Br J Surg 2005;92:1155-1160.

166. Huh JW, Cho CK, Kim HR, Kim YJ. Impact of resection for primary colorectal cancer on outcomes in patients with synchronous colorectal liver metastases. J Gastrointest Surg 2010;14:1258-1264.

167. Michel P, Roque I, Di Fiore F, et al. Colorectal cancer with nonresectable synchronous metastases: should the primary tumor be resected? Gastroenterol Clin Biol 2004;28:434-437.

168. Tebbutt NC, Norman AR, Cunningham D, et al. Intestinal complications after chemotherapy for patients with unresected primary colorectal cancer and synchronous metastases. Gut 2003;52:568-573.

169. Adam R, Delvart V, Pascal G, et al. Rescue surgery for unresectable colorectal liver metastases downstaged by chemotherapy: a model to predict long-term survival. Ann Surg 2004;240:644-657; discussion 657-648.

170. Galfrascoli E, Piva S, Cinquini M, et al. Risk/benefit profile of bevacizumab in metastatic colon cancer: a systematic review and meta-analysis. Dig Liver Dis 2011;43:286-294.

171. Chua TC, Saxena A, Liauw W, Kokandi A, Morris DL. Systematic review of randomized and nonrandomized trials of the clinical response and outcomes of neoadjuvant systemic chemotherapy for resectable colorectal liver metastases. Ann Surg Oncol 2010;17:492-501.

172. Gallagher DJ, Zheng J, Capanu M, et al. Response to neoadjuvant chemotherapy does not predict overall survival for patients with synchronous colorectal hepatic metastases. Ann Surg Oncol 2009;16:1844-1851.

173. Merkel S, Bialecki D, Meyer T, et al. Comparison of clinical risk scores predicting prognosis after resection of colorectal liver metastases. J Surg Oncol 2009;100:349-357.

174. Pawlik TM, Assumpcao L, Vossen JA, et al. Trends in nontherapeutic laparotomy rates in patients undergoing surgical therapy for hepatic colorectal metastases. Ann Surg Oncol 2009;16:371-378.

175. Brouquet A, Mortenson MM, Vauthey JN, et al. Surgical strategies for synchronous colorectal liver metastases in 156 consecutive patients: classic, combined or reverse strategy? J Am Coll Surg 2010;210:934-941.

176. Mentha G, Majno PE, Andres A, et al. Neoadjuvant chemotherapy and resection of advanced synchronous liver metastases before treatment of the colorectal primary. Br J Surg 2006;93:872-878.

177. Poultsides GA, Servais EL, Saltz LB, et al. Outcome of primary tumor in patients with synchronous stage IV colorectal cancer receiving combination chemotherapy without surgery as initial treatment. J Clin Oncol 2009;27:3379-3384.

178. Shin SJ, Yoon HI, Kim NK, et al. Upfront systemic chemotherapy and preoperative short-course radiotherapy with delayed surgery for locally advanced rectal cancer with distant metastases. Radiat Oncol 2011;6:99.

179. Zalinski S, Abdalla EK, Mahvash A, Vauthey JN. A marking technique for intraoperative localization of small liver metastases before systemic chemotherapy. Ann Surg Oncol 2009;16:1208-1211.

180. Chen J, Li Q, Wang C, et al. Simultaneous vs. staged resection for synchronous colorectal liver metastases: a metaanalysis. Int $J$ Colorectal Dis 2011;26:191-199.

181. Fahy BN, Fischer CP. Synchronous resection of colorectal primary and hepatic metastasis. J Gastrointest Oncol 2012;3:48-58.

182. Martin RC, $2^{\text {nd }}$, Augenstein V, Reuter NP, Scoggins CR, McMasters KM. Simultaneous versus staged resection for synchronous colorectal cancer liver metastases. J Am Coll Surg 2009;208:842850; discussion 850-842.

183. Mayo SC, Pulitano C, Marques H, et al. Surgical management of patients with synchronous colorectal liver metastasis: a multicenter international analysis. J Am Coll Surg 2013;216:707716; discussion 716-708.

184. Reddy SK, Pawlik TM, Zorzi D, et al. Simultaneous resections of colorectal cancer and synchronous liver metastases: a multiinstitutional analysis. Ann Surg Oncol 2007; 14:3481-3491.

185. Turrini O, Viret F, Guiramand J, et al. Strategies for the treatment of synchronous liver metastasis. Eur J Surg Oncol 2007;33:735-740.

186. Yan TD, Chu F, Black D, King DW, Morris DL. Synchronous resection of colorectal primary cancer and liver metastases. World J Surg 2007;31:1496-1501.

187. Abbott AM, Parsons HM, Tuttle TM, Jensen EH. Shortterm outcomes after combined colon and liver resection for synchronous colon cancer liver metastases: a population study. Ann Surg Oncol 2013;20:139-147.

188. Thelen A, Jonas S, Benckert C, et al. Simultaneous versus staged liver resection of synchronous liver metastases from colorectal cancer. Int J Colorectal Dis 2007;22:1269-1276.

189. Nakajima K, Takahashi S, Saito N, et al. Efficacy of the predicted operation time (POT) strategy for synchronous colorectal liver metastasis (SCLM): feasibility study for staged resection in patients with a long POT. J Gastrointest Surg 2013;17:688-695.

190. Fahy BN, D’Angelica M, DeMatteo RP, et al. Synchronous hepatic metastases from colon cancer: changing treatment strategies and results of surgical intervention. Ann Surg Oncol 2009;16:361-370.

191. Kim JW, Kim YB, Kim NK, et al. The role of adjuvant pelvic radiotherapy in rectal cancer with synchronous liver metastasis: a retrospective study. Radiat Oncol 2010;5:75.

192. Butte JM, Gonen M, Ding P, et al. Patterns of failure in patients with early onset (synchronous) resectable liver metastases from rectal cancer. Cancer 2012;118:5414-5423.

193. Mentha G, Roth AD, Terraz S, et al. 'Liver first' approach in the treatment of colorectal cancer with synchronous liver metastases. Dig Surg 2008;25:430-435.

194. Polignano FM, Quyn AJ, Sanjay P, Henderson NA, Tait IS. Totally laparoscopic strategies for the management of colorectal cancer with synchronous liver metastasis. Surg Endosc 2012;26:25712578.

195. Aoki T, Umekita N, Tanaka S, et al. Prognostic value of concomitant resection of extrahepatic disease in patients with liver metastases of colorectal origin. Surgery 2008;143:706-714.

196. Dexiang Z, Li R, Ye W, et al. Outcome of patients with colorectal liver metastasis: analysis of 1,613 consecutive cases. Ann Surg Oncol 2012;19:2860-2868.

197. Haruki K, Shiba H, Fujiwara Y, et al. Perioperative change in peripheral blood monocyte count may predict prognosis in patients with colorectal liver metastasis after hepatic resection. J Surg Oncol 2012;106:31-35.

198. Hayashi M, Inoue Y, Komeda K, et al. Clinicopathological analysis of recurrence patterns and prognostic factors for survival after hepatectomy for colorectal liver metastasis. BMC Surg 2010;10:27.

199. Hill CR, Chagpar RB, Callender GG, et al. recurrence following hepatectomy for metastatic colorectal cancer: development of a model that predicts patterns of recurrence and survival. Ann Surg Oncol 2012;19:139-144.

200. Inoue Y, Hayashi M, Komeda K, et al. Resection margin with anatomic or nonanatomic hepatectomy for liver metastasis from colorectal cancer. J Gastrointest Surg 2012;16:1171-1180.

201. Shiba H, Ishida Y, Haruki K, et al. Negative impact of freshfrozen plasma transfusion on prognosis after hepatic resection for liver metastases from colorectal cancer. Anticancer Res 2013;33:2723-2728.

202. Wang Y, Liu YF, Cheng Y, et al. Prognosis of colorectal cancer with liver metastasis: value of a prognostic index. Braz J Med Biol Res 2010;43:1116-1122.

203. Huang CJ, Teng HW, Chien CC, Lin JK, Yang SH. Prognostic 
significance of C-reactive protein polymorphism and KRAS/ BRAF in synchronous liver metastasis from colorectal cancer. PLoS One 2013;8:e65117.

204. Nanashima A, Araki M, Tobinaga S, et al. Relationship between period of survival and clinicopathological characteristics in patients with colorectal liver metastasis. Eur J Surg Oncol 2009;35:504-509.

205. Takahashi S, Konishi M, Kinoshita T, et al. Predictors for early recurrence after hepatectomy for initially unresectable colorectal liver metastasis. J Gastrointest Surg 2013;17:939-948.

206. Gomez D, Morris-Stiff G, Wyatt J, et al. Surgical technique and systemic inflammation influences long-term disease-free survival following hepatic resection for colorectal metastasis. J Surg Oncol 2008;98:371-376.

207. Schepers A, Mieog S, van de Burg BB, et al. Impact of complications after surgery for colorectal liver metastasis on patient survival. J Surg Res 2010;164:e91-97.

208. Halazun KJ, Aldoori A, Malik HZ, et al. Elevated preoperative neutrophil to lymphocyte ratio predicts survival following hepatic resection for colorectal liver metastases. Eur J Surg Oncol 2008;34:55-60.

209. Cheng KC, Yeung YP, Lau PY, Meng WC. Surveillance and outcome of liver metastasis in patients with colorectal cancer who had undergone curative-intent operation. Hong Kong Med J 2008; 14:432-436.

210. de Jong MC, Mayo SC, Pulitano C, et al. Repeat curative intent liver surgery is safe and effective for recurrent colorectal liver metastasis: results from an international multi-institutional analysis. J Gastrointest Surg 2009;13:2141-2151.

211. Neeff HP, Drognitz O, Holzner P, et al. Outcome after repeat resection of liver metastases from colorectal cancer. Int $J$ Colorectal Dis 2013;28:1135-1141.

212. Uskudar O, Raja K, Schiano TD, et al. Liver transplantation is possible in some patients with liver metastasis of colon cancer. Transplant Proc 2011;43:2070-2074.

213. Lee WS, Yun HR, Yun SH, et al. Treatment outcomes of hepatic and pulmonary metastases from colorectal carcinoma. J Gastroenterol Hepatol 2008;23:e367-372.

214. Jayne DG, Fook S, Loi C, Seow-Choen F. Peritoneal carcinomatosis from colorectal cancer. Br J Surg 2002;89:1545-1550.

215. Sargent DJ, Marsoni S, Monges G, et al. Defective mismatch repair as a predictive marker for lack of efficacy of fluorouracil-based adjuvant therapy in colon cancer. J Clin Oncol 2010;28:3219-3226.

216. Verwaal VJ, van Ruth S, de Bree E, et al. Randomized trial of cytoreduction and hyperthermic intraperitoneal chemotherapy versus systemic chemotherapy and palliative surgery in patients with peritoneal carcinomatosis of colorectal cancer. J Clin Oncol 2003;21:3737-3743.

217. Elias D, Blot F, El Otmany A, et al. Curative treatment of peritoneal carcinomatosis arising from colorectal cancer by complete resection and intraperitoneal chemotherapy. Cancer 2001;92:71-76.

218. Elias D, Delperro JR, Sideris L, et al. Treatment of peritoneal carcinomatosis from colorectal cancer: impact of complete cytoreductive surgery and difficulties in conducting randomized trials. Ann Surg Oncol 2004;11:518-521.

219. Elias D, Gilly F, Boutitie F, et al. Peritoneal colorectal carcinomatosis treated with surgery and perioperative intraperitoneal chemotherapy: retrospective analysis of 523 patients from a multicentric French study. J Clin Oncol 2010;28:63-68.

220. Elias D, Matsuhisa T, Sideris L, et al. Heated intra-operative intraperitoneal oxaliplatin plus irinotecan after complete resection of peritoneal carcinomatosis: pharmacokinetics, tissue distribution and tolerance. Ann Oncol 2004;15:1558-1565.

221. Glehen O, Kwiatkowski F, Sugarbaker PH, et al. Cytoreductive surgery combined with perioperative intraperitoneal chemotherapy for the management of peritoneal carcinomatosis from colorectal cancer: a multi-institutional study. J Clin Oncol 2004;22:3284-3292.

222. Kecmanovic DM, Pavlov MJ, Ceranic MS, et al. Treatment of peritoneal carcinomatosis from colorectal cancer by cytoreductive surgery and hyperthermic perioperative intraperitoneal chemotherapy. Eur J Surg Oncol 2005;31:147-152.

223. Mahteme H, Hansson J, Berglund A, et al. Improved survival in patients with peritoneal metastases from colorectal cancer: a preliminary study. Br J Cancer 2004;90:403-407.

224. Pilati P, Mocellin S, Rossi CR, et al. Cytoreductive surgery combined with hyperthermic intraperitoneal intraoperative chemotherapy for peritoneal carcinomatosis arising from colon adenocarcinoma. Ann Surg Oncol 2003;10:508-513.

225. Shen P, Hawksworth J, Lovato J, et al. Cytoreductive surgery and intraperitoneal hyperthermic chemotherapy with mitomycin C for peritoneal carcinomatosis from nonappendiceal colorectal carcinoma. Ann Surg Oncol 2004;11:178-186.

226. Sugarbaker PH, Schellinx ME, Chang D, Koslowe P, von Meyerfeldt M. Peritoneal carcinomatosis from adenocarcinoma of the colon. World J Surg 1996;20:585-591; discussion 592.

227. Witkamp AJ, de Bree E, Kaag MM, et al. Extensive cytoreductive surgery followed by intra-operative hyperthermic intraperitoneal chemotherapy with mitomycin-C in patients with peritoneal carcinomatosis of colorectal origin. Eur J Cancer 2001;37:979-984.

228. Yan TD, Black D, Savady R, Sugarbaker PH. Systematic review on the efficacy of cytoreductive surgery combined with perioperative intraperitoneal chemotherapy for peritoneal carcinomatosis from colorectal carcinoma. J Clin Oncol 2006;24:4011-4019.

229. Cao C, Yan TD, Black D, Morris DL. A systematic review and meta-analysis of cytoreductive surgery with perioperative intraperitoneal chemotherapy for peritoneal carcinomatosis of colorectal origin. Ann Surg Oncol 2009;16:2152-2165.

230. Yan TD, Morris DL. Cytoreductive surgery and perioperative intraperitoneal chemotherapy for isolated colorectal peritoneal carcinomatosis: experimental therapy or standard of care? Ann Surg 2008;248:829-835.

231. Sadeghi B, Arvieux C, Glehen O, et al. Peritoneal carcinomatosis from non-gynecologic malignancies: results of the EVOCAPE 1 multicentric prospective study. Cancer 2000;88:358-363.

232. Stephens AD, Alderman R, Chang D, et al. Morbidity and mortality analysis of 200 treatments with cytoreductive surgery and hyperthermic intraoperative intraperitoneal chemotherapy using the coliseum technique. Ann Surg Oncol 1999;6:790-796.

233. Sugarbaker PH, Jablonski KA. Prognostic features of 51 colorectal and 130 appendiceal cancer patients with peritoneal carcinomatosis treated by cytoreductive surgery and intraperitoneal chemotherapy. Ann Surg 1995;221:124-132.

234. Glehen O, Mithieux F, Osinsky D, et al. Surgery combined with peritonectomy procedures and intraperitoneal chemohyperthermia in abdominal cancers with peritoneal carcinomatosis: a phase II study. J Clin Oncol 2003;21:799-806.

235. Pestieau SR, Sugarbaker PH. Treatment of primary colon cancer with peritoneal carcinomatosis: comparison of concomitant vs. delayed management. Dis Colon Rectum 2000;43:1341-1346; discussion 1347-1348.

236. Shen P, Levine EA, Hall J, et al. Factors predicting survival after intraperitoneal hyperthermic chemotherapy with mitomycin C after cytoreductive surgery for patients with peritoneal carcinomatosis. Arch Surg 2003;138:26-33.

237. Franko J, Ibrahim Z, Gusani NJ, et al. Cytoreductive surgery and hyperthermic intraperitoneal chemoperfusion versus systemic chemotherapy alone for colorectal peritoneal carcinomatosis. Cancer 2010;116:3756-3762. 
238. Roth ES, Fetzer DT, Barron BJ, et al. Does colon cancer ever metastasize to bone first? a temporal analysis of colorectal cancer progression. BMC Cancer 2009;9:274.

239. Labianca R, Nordlinger B, Beretta GD, et al. Primary colon cancer: ESMO Clinical Practice Guidelines for diagnosis, adjuvant treatment and follow-up. Ann Oncol 2010;21(Suppl 5):v70-77.

240. Meyerhardt JA, Mangu PB, Flynn PJ, et al. Follow-up care, surveillance protocol, and secondary prevention measures for survivors of colorectal cancer: American Society of Clinical Oncology clinical practice guideline endorsement. J Clin Oncol
2013;31:4465-4470.

241. Choi J. Imaging of hepatic metastases. Cancer Control 2006;13:612.

242. Trillaud H, Bruel JM, Valette PJ, et al. Characterization of focal liver lesions with SonoVue-enhanced sonography: international multicenter-study in comparison to CT and MRI. World $J$ Gastroenterol 2009;15:3748-3756.

243. Pfister DG, Benson AB, $3^{\text {rd }}$, Somerfield MR. Clinical practice. Surveillance strategies after curative treatment of colorectal cancer. N Engl J Med 2004;350:2375-2382. 